Canadian

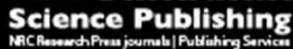

Canadian Geotechnical Journal Revue canadienne de géotechnique

\title{
Measuring Unsaturated Soil Deformations during Triaxial Testing Using A Photogrammetry-Based Method
}

\begin{tabular}{|r|l|}
\hline Journal: & Canadian Geotechnical Journal \\
\hline Manuscript ID & cgj-2015-0038.R1 \\
\hline Manuscript Type: & Article \\
\hline Date Submitted by the Author: & 16 -Jul-2015 \\
\hline Complete List of Authors: & $\begin{array}{l}\text { Li, Lin; University of Alaska Fairbanks, Department of Civil and } \\
\text { Environmental Engineering } \\
\text { Zhang, Xiong; University of Alaska Fairbanks, Department of Civil and } \\
\text { Environmental Engineering } \\
\text { Chen, Gang; University of Alaska Fairbanks, Department of Mining and } \\
\text { Geological Engineering } \\
\text { Lytton, Robert; Texas A\&M University, Zachry Department of Civil } \\
\text { Engineering }\end{array}$ \\
\hline Keyword: & $\begin{array}{l}\text { optical ray tracing, strain localization, unsaturated soil, triaxial test, volume } \\
\text { change }\end{array}$ \\
\hline &
\end{tabular}

\section{SCHOLARONE \\ Manuscripts}




\title{
Measuring Unsaturated Soil Deformations during Triaxial Testing Using a Photogrammetry-Based Method
}

\author{
Lin $\mathrm{Li}^{1}$, Xiong Zhang ${ }^{2}$, Gang $\mathrm{Chen}^{3}$, and Robert Lytton ${ }^{4}$
}

\author{
Lin Li, Ph. D \\ Department of Civil and Environmental Engineering \\ University of Alaska Fairbanks, Fairbanks, AK, 99775-1157 \\ Phone: 907-474-5786, Fax: 907-474-6030, Email: 1li10@alaska.edu
}

Xiong Zhang, Ph. D, P.E., Associate Professor

Department of Civil and Environmental Engineering

University of Alaska Fairbanks, Fairbanks, AK, 99775-5900

Phone: 907-474-6172, Fax: 907-474-6030, Email: xzhang11@alaska.edu

Gang Chen, Ph. D, P.E., Professor

Department of Mining and Geological Engineering

University of Alaska Fairbanks, AK 99775-5880

Phone: 907-474-6875, Fax: 907-474-6635, Email: gchen@alaska.edu

Robert L. Lytton, Benson Chair Professor

Zachry Department of Civil Engineering

Texas A\&M University, College Station, TX 77843-3136

Phone: 979-845-9964, Email: r-lytton@tamu.edu 


\section{ABSTRACT}

When characterizing an unsaturated soil using the triaxial test apparatus, it is required to measure the soil deformation during loading. Recently, a photogrammetry-based method has been developed for total and localized volume change measurements on unsaturated soils during triaxial testing. In this study, more in-depth discussions on the photogrammetry-based method are addressed such as system setup, measurement procedure, accuracy self-check, data postprocessing, and differences from the conventional image-based methods. Also, an application of the photogrammetry-based method on unsaturated soil deformation measurements is presented through a series of undrained triaxial tests with different loading paths. After testing, threedimensional (3D) models of the tested soils at different loading steps were constructed based on the $3 \mathrm{D}$ coordinates of measurement targets on the soil surface. Clear barreling processes for soils during deviatoric loading were observed through the constructed $3 \mathrm{D}$ models at different axial strain levels. Soil volume changes and volumetric strain non-uniformities during isotropic and deviatoric loadings were extracted based upon detailed analyses on different soil layers. Through a full-field strain distribution analysis, a shear band evolution process was captured for the soil during deviatoric loading at a low confining stress. The photogrammetry-based method proved to be very powerful for in-depth soil deformation characteristics investigation.

KEYWORDS: photogrammetry-based method; optical ray tracing; triaxial test; unsaturated soil; volume change; strain localization 


\section{INTRODUCTION}

Triaxial test is commonly used to characterize both saturated and unsaturated soils. The volume or volume change of a soil is an essential parameter in understanding the deformation and strength properties of the soil. For triaxial test on a saturated soil, soil volume change can be directly measured through monitoring water exchange. For an unsaturated soil, due to the presence of air phase, the soil volume change is no longer equal to the change in water volume. As a result, the conventional method to measure volume change of saturated soils cannot be used any more. In the past few decades, several methods has been developed to measure unsaturated soil volume changes during triaxial testing as summarized by Geiser et al. (2000), Sharma et al. (2006), Laloui et al. (2006), Hoyos et al. (2009), and Zhang et al. (2015).

Double-wall cell method, proposed by Bishop and Donald (1961) as shown in Fig. 1(a), is the most extensively used method for unsaturated soil volume change measurements. An inner cell was added to the conventional triaxial test apparatus and equal cell pressure was applied on both sides to ensure no lateral deformation of the inner cell. The volume change of the soil was then deduced by measuring the variation of the mercury level in the inner cell. Several modifications were made on the double-wall cell method later by Wheeler (1988), Cui and Delage (1996), and Ng et al. (2002). However, the principles of the volume change measurement were the same. The double-wall cell method requires major equipment modifications on the conventional triaxial test apparatus for saturated soils and is therefore expensive. A typically double-wall cell triaxial testing system costs over $\$ 100,000$ and is complex to operate. The volume change measurement accuracy can be influenced by water absorption of the inner cell. The water absorption is sensitive to chamber pressure, temperature, and time which make the system calibration extremely difficult. Steel inner cell can be an alternative to solve the water 
absorption problem. However, for this non-transparent inner cell, it is difficult to examine the existence of air bubbles in the chamber which are difficult to be removed. These air bubbles can also influence the volume change measurement accuracy. A carefully calibrated double-wall cell can measure total volume change to an accuracy of $0.25 \%$ (GDS 2009).

Besides the double-wall cell method, some other methods have also been developed to measure the volume change of unsaturated soils such as direct measurements of the air and water volumes using digital pressure volume controllers (Adams et al. 1996; Geiser 1999; and Laudahn et al. 2005), local displacement measurement using miniature LVDTs (Clayton et al. 1989), Hall Effect transducers (Clayton and Khatrush 1986), and profile determination using laser scanners (Romero et al. 1997). As pointed out by Geiser et al. (2000), Sharma et al. (2006), Hoyos et al. (2009), and Zhang et al. (2015), these methods also have their limitations and were not widely used.

With the increasing availability of inexpensive digital cameras, more and more image-based methods have been developed for soil deformation measurements during triaxial testing. The most widely used image-based method is presented by Macari et al. (1997). A stationary camera was mounted "far away" from the triaxial system. Images were captured for the soil specimen in the triaxial cell during loading. A two-dimensional (2D) refraction correction model (Parker 1987) was adopted to correct the magnification due to refractions caused by the confining fluid and triaxial cell wall as schematically shown in Fig. 1(b). By detecting the edges of the specimen through the captured images, volume changes of the tested specimen were computed by assuming the soil specimen always maintains a circular shape at any height. The advantage of this method lies in its simplicity: a conventional triaxial cell could be used without any modification. For this image-based method, only a 2D image of the specimen can be obtained for 
each measurement. As shown in Fig. 1(b), for points at locations of $P, P_{1}$, and $P_{2}$, their positons on the captured 2D image are the same. Since the soil deformation during triaxial testing is in 3D, soil 3D deformation cannot be obtained unless two requirements were satisfied: (1) when deforming, the deformation occurs exactly along the radial direction; and (2) soil remains to be axisymmetric after deforming. Also, to apply the 2D refraction correction model, some other requirements are needed to be satisfied: (1) the soil specimen and the confining acrylic chamber are perfectly cylindrical and installed vertically; (2) the shooting direction of the digital pinhole camera exactly passes through the center of the chamber as shown in Fig. 1(b); (3) the soil specimen is installed exactly at the center of the confining chamber which is also shown in Fig. 1(b); (4) deformation of the acrylic cell wall under water pressure is negligible; and (5) the relative positions of the pinhole camera, triaxial chamber, and the soil specimen are accurately known. With the similar system setup and refraction correction model, Lin and Penumadu (2006) presented a new image-based method to analyze the soil deformations in a series of combined axial-torsional tests under undrained condition. Instead of edge detecting, measurement points in a grid pattern with spacing of $10 \mathrm{~mm}$ were marked on the membrane which covered the soil specimen. The movements of these measurement points were tracked during testing through digital image analysis technique. The system setup in Macari et al. (1997) was also adopted by Gachet et al. (2007) to measure soil volume changes during triaxial testing. However, in this case, several calibrations, which included perspective correction, axial, and radial calibrations, were performed as a replacement of the $2 \mathrm{D}$ refraction correction model to correct the magnification effect due to the confining fluid and triaxial cell wall. For these image-based methods (Macari et al. 1997; Lin and Penumadu 2006; and Gachet et al. 2007), due to the difficulties in accurate determine the locations of the camera station and the triaxial cell for 
refraction correction, a sophisticated system calibration is required for volume change measurement. Furthermore, the measurement accuracy of the image-based methods is not high. As addressed in Lin and Penumadu (2006), the obtained measurement accuracy was reported to be $0.2 \mathrm{~mm}$ and $0.3 \mathrm{~mm}$ in the vertical and circumferential directions, respectively. In Gachet et al. (2007), the volume measurement accuracy was determined to be $0.6 \%$.

According to recent findings (Alshibli et al. 2000; Rechenmacher and Saab 2002; Desrues 2004; and Rechenmacher 2006), in addition to volume change, localized deformation also has a significant impact on soil behavior. As addressed in Sachan and Penumadu (2007), strain localization is considered to be a major factor which controls the overall mechanical response of the soil, at or near failure. The developments of appropriate constitutive models for these soils and the appropriate quantification of their failure states depend on accurate experimental quantification of shear band formation, growth, and evolution. Meanwhile, more and more attention was drawn on the investigation of localized deformation in soil during triaxial testing (Lin and Penumadu 2006; Rechenmacher 2006; Sachan and Penumadu 2007; Rechenmacher and Medina-Cetina 2007; and Bhandari et al. 2012).

In Lin and Penumadu (2006) and Sachan and Penumadu (2007), strain localization was obtained based on the deformation of the point grid. Different from the digital image analysis method, digital image correlation (DIC) technique was reported to be utilized for soil deformation measurements under triaxial condition (Rechenmacher 2006; Rechenmacher and Medina-Cetina 2007; and Bhandari et al. 2012). When using the DIC technique, the displacement measurement was derived by mapping, between digital images, overlapping subsets of pixels or overlapping clusters of sand grains at many points across the specimen surface. However, in Rechenmacher (2006) and Rechenmacher and Medina-Cetina (2007), due 
to the difficulties in dealing with refraction, DIC cannot be directly used for deformation measurements on soils located in a triaxial chamber with or without confining fluid. Instead, the confining load was applied through vacuum pressure. Therefore, the applied confining load was limited to less than $100 \mathrm{kPa}$. Bhandari et al. (2012) reported the use of DIC technique for soil deformation measurements under triaxial condition. A 3D refraction model was developed to deal with the refractions at the interfaces of air-cell and cell-water. Three cameras around the testing system at intervals of $120^{\circ}$ were used to capture images of a deforming soil specimen at various instants. However, this deformation measurement using the DIC technique suffered most of the same limitations from as those in the image-based methods Macari et al. (1997), Lin and Penumadu (2006), and Gachet et al. (2007) due to a similar system setup.

Till now, quantitative full-field 3D deformation measurement on unsaturated soils remains a great challenge for researchers. As a result, the full-field deformation measurement on an unsaturated soil during triaxial testing has never been investigated due to lack of a suitable measurement method with acceptable cost and accuracy. Recently, Zhang et al. (2015) proposed a new photogrammetry-based method to measure total and localized deformation of unsaturated soils during triaxial testing. In Zhang et al. (2015), the principle and mathematical derivation of the photogrammetry-based method were presented. Validation tests were performed on a stainless steel cylinder and a saturated sand specimen. The average point position and volume change measurement accuracies were evaluated to be $0.065 \mathrm{~mm}$ and $0.05 \%$, respectively. In this study, more in-depth discussions on this newly developed photogrammetry-based method are made which included system setup, measurement procedure, accuracy self-check, data postprocessing, and differences from the conventional image-based methods. Also, to better understand the capabilities of the photogrammetry-based method for deformation measurement 
on unsaturated soils, a series of undrained triaxial tests were conducted during which soil deformations were measured through monitoring the 3D coordinates of measurement targets on soil surface. After testing, soil deformation characteristics such as total volume change, volumetric strain non-uniformity, barreling, shear band evolution, and full-field strain distribution during triaxial testing were obtained using the photogrammetry-based measurement method.

\section{A PHOTOGRAMMETRY-BASED METHOD}

\section{Measurement System Setup}

The method proposed by Zhang et al. (2015) uses a conventional triaxial test apparatus and a commercially available digital camera to measure total and localized volume changes of unsaturated soils. The digital single lens reflex camera (Nikon D7000 with a $50 \mathrm{~mm}$ fixed focal length lens as shown in Fig. 2(a)), which was used in Zhang et al. (2015), was also used in this study. System setup included posting some measurement targets on the load frame, the surface of the acrylic cell and the surface of the tested soil specimen as shown in Fig. 2(b). These targets are high contrast dots with unique rings around them which can be identified automatically by software (i.e. PhotoModeler Scanner).

The measurement targets posted on the load frame were used to facilitate the establishment of a 3D global coordinate system as shown in Fig. 2(b) for reconstructing the 3D models of the soil specimen during triaxial testing, which will be explained later. The measurement targets posted on the acrylic cell of the triaxial test apparatus were used to define the shape and location of the acrylic cell. Theoretically speaking, the more measurement targets on the acrylic cell, the more accurate the shape and location of the acrylic cell can be determined. However, too many 
measurement targets could block the view to the soil specimen located inside the triaxial chamber. These targets can potentially increase the number of pictures needed to reconstruct the 3D model of the soil specimen. To overcome this limitation, it is preferable to post more measurement targets on the two ends and less targets at the middle of the acrylic cell. A typical example is shown in Fig. 2(b), six circles of measurement targets (45 targets / circle) and three columns of targets (18 targets / column) were posted on the two ends and the middle of the acrylic cell, respectively. The measurement targets posted on the surface of the soil specimen were used to define the shape and location of the soil specimen for deformation measurements. During triaxial testing, the soil specimen was often enclosed in a rubber membrane to separate the soil specimen from the confining fluid. As a result, the measurement targets were directly posted on the rubber membrane as shown in Fig. 2(b) after the specimen installation. The more measurement targets on the rubber membrane, the more detailed deformation can be extracted. It is also worth noting that although the photogrammetry-based method was developed for measuring deformation of unsaturated soils, it can also be applied to triaxial test on saturated soils.

\section{Measurement Principle}

The photogrammetry-based method proposed by Zhang et al. (2015) is based upon the principle of photogrammetry (close-range photogrammetry to be specific). Photogrammetry, which is the science of making measurements from photographs, has been used for more than 100 years. The fundamental principle of photogrammetry is triangulation (Mikhail et al. 2001). By taking photographs from at least two different locations, common points are identified on each image and so-called "lines of sight" can be developed from each camera to points on the 
object. These lines of sight (sometimes called rays owing to their optical nature) are mathematically intersected (referred as "coplanarity" in photogrammetry) to produce the 3D coordinates of the points of interest as well as the camera positions. Figs. 2(b) and 2(d) show two of 22 photographs taken at camera stations of 1 and 9, respectively. Fig. 2(c) shows camera stations (labelled as "CS") and measurement target positions posted on the load frame and the surface of the acrylic cell, which were determined by photogrammetry.

Photogrammetry can be used to determine the 3D coordinates of the points of interest in one optical medium in which a light ray travels along a straight line. However, it cannot be directly used to reconstruct the 3D model of an unsaturated soil specimen during triaxial testing since the soil specimen is submerged in the confining fluid inside the acrylic cell. Due to the refraction effects at the air-acrylic cell and acrylic cell-water interfaces, light ray bends. By integrating photogrammetry, optical ray tracing, and least square optimization, Zhang et al. (2015) extended the application of photogrammetry from one optical medium to multiple optical media conditions. The principle of the photogrammetry-based method is summarized using Figs. 2 and 3 in the following sections.

In Zhang et al. (2015), the camera positions and the 3D coordinates of the measurement points on the acrylic cell were determined using the photogrammetry in the global coordinate system as shown in Fig. 2(b). In order to measure the 3D coordinates of a point on the soil surface, for example point 93 in Fig. 2(d) (which corresponds to $P$ in Fig. 3), the position of the point $I$ on the image in the corresponding local camera coordinate system $(x-y-z)$ is determined to be $\left(x_{I}, y_{I},-f\right)$ based on the pinhole camera model. Once the camera orientation (which includes the location of the principal point $S\left(X_{s}, Y_{s}, Z_{s}\right)$ and three rotation angles $\left.\kappa, \omega, \varphi\right)$ are known 
from a standard photogrammetry analysis, the $3 \mathrm{D}$ coordinates of the image point $I$ in the global coordinate system $(X-Y-Z)$ in Fig. 3 can be calculated using eq. [1].

[1] $\left(\begin{array}{l}X_{I} \\ Y_{I} \\ Z_{I}\end{array}\right)=R(\omega, \varphi, \kappa)\left(\begin{array}{c}x_{I} \\ y_{I} \\ -f\end{array}\right)+\left(\begin{array}{l}X_{s} \\ Y_{s} \\ Z_{s}\end{array}\right)$

where,

$X_{I}, Y_{I}, Z_{I}=3 \mathrm{D}$ coordinates of the point on the image in the global coordinate system as shown in Fig. 3,

$R(\omega, \varphi, \kappa)=\left(\begin{array}{lcc}\cos \kappa \cos \varphi & -\sin \kappa \cos \varphi & \sin \varphi \\ \cos \kappa \sin \omega \sin \varphi+\sin \kappa \cos \omega & -\sin \kappa \sin \omega \sin \varphi+\cos \kappa \cos \omega & -\sin \omega \cos \varphi \\ -\cos \kappa \cos \omega \sin \varphi+\sin \kappa \sin \omega & \sin \kappa \sin \varphi \cos \omega+\cos \kappa \sin \omega & \cos \omega \cos \varphi\end{array}\right)$

$\kappa, \omega, \varphi=$ three rotational angles from the global coordinate system to the local camera coordinate system $(x-y-z)$ (rotates about $\mathrm{X}$, then $\mathrm{Y}$, then $\mathrm{Z}$ axis) as shown in Fig. 3,

$x_{I}, y_{I}=$ coordinates of the point $I$ on the image in the local camera coordinate system as shown in Fig. 3,

$f \quad=$ camera focal length, and

$X_{s}, Y_{s}, Z_{s}=3 \mathrm{D}$ coordinates of the camera station in the global coordinate system as shown in Fig. 3.

With known 3D coordinates of points $S$ and $I$ in the global coordinate system, the tracing ray SI is known. In the Zhang et al. (2015), the acrylic cell was assumed to be barrel-shaped as represented by the following equation: 
[2] $\left[\begin{array}{l}X-X_{R} \\ Y-Y_{R} \\ Z-Z_{R}\end{array}\right]^{T} R_{1}^{T}\left[\begin{array}{ccc}1 & 0 & 0 \\ 0 & -A & 0 \\ 0 & 0 & 1\end{array}\right] R_{1}\left[\begin{array}{l}X-X_{R} \\ Y-Y_{R} \\ Z-Z_{R}\end{array}\right]-\left[\begin{array}{l}X-X_{R} \\ Y-Y_{R} \\ Z-Z_{R}\end{array}\right]^{T} R_{1}^{T}\left[\begin{array}{l}0 \\ B \\ 0\end{array}\right]-C=0$

where,

$X_{R}, Y_{R}, Z_{R}=3 \mathrm{D}$ coordinates of the origin of the local cell coordinate system in the global coordinate system as shown in Fig. 3,

$R_{1}=\left(\begin{array}{llc}\cos \varphi^{\prime} \cos \kappa^{\prime} & \cos \omega^{\prime} \sin \kappa^{\prime}+\sin \omega^{\prime} \sin \varphi^{\prime} \cos \kappa^{\prime} & \sin \omega^{\prime} \sin \kappa^{\prime}-\cos \omega^{\prime} \sin \varphi^{\prime} \cos \kappa^{\prime} \\ -\cos \varphi^{\prime} \sin \kappa^{\prime} & \cos \omega^{\prime} \cos \kappa^{\prime}-\sin \omega^{\prime} \sin \varphi^{\prime} \sin \kappa^{\prime} & \sin \omega^{\prime} \cos \kappa^{\prime}+\cos \omega^{\prime} \sin \varphi^{\prime} \sin \kappa^{\prime} \\ \sin \varphi^{\prime} & -\sin \omega^{\prime} \cos \varphi^{\prime} & \cos \omega^{\prime} \cos \varphi^{\prime}\end{array}\right)$,

$\kappa^{\prime}, \omega^{\prime}, \phi^{\prime} \quad=\quad$ rotational angles from global coordinate system to the local cell coordinate system (rotates about $\mathrm{X}$, then $\mathrm{Y}$, then $\mathrm{Z}$ axis), and

$A, B$, and $C=$ coefficients determine the deformed shape of the acrylic cell surface. $\mathrm{C}$ is the square of radius of the outer surface of the acrylic cell before deformation.

The shape and location of the outer surface of the acrylic cell were determined by photogrammetry using the measurement targets posted on the acrylic cell as shown in Fig. 2(b). The cell wall reconstruction is performed to determine the nine parameters (i.e. $A, B, C, X_{R}, Y_{R}$, $\left.\left.Z_{R}, \kappa^{\prime}, \omega^{\prime}, \varphi^{\prime}\right)\right)$ by best-fit eq. [2] with 3D coordinates of targets on the outer surface of the acrylic cell using a least-square method.

With the known incident ray SI and the shape and location of the acrylic cell (defined by eq. [2]), the intercept point $D$ of the incident ray $S I$ at the acrylic cell surface can be solved. The normal of the acrylic cell at point $D$ can be determined by differentiating eq. [2] at point $D$.

With the known incident ray $S D\left(\vec{r}_{i}\right)$, incident point $D$ on the acrylic cell outer surface, the normal of the acrylic cell at point $D(\vec{n})$, and refractive indices of air and the acrylic cell $\left(n_{i}\right.$ and 
$n_{r}$ ), the direction of the refracted ray $\vec{r}_{r}$ after refraction can be calculated using the Snell's law in 3D space as shown in eq. [3] (Zhang et al. 2015).

[3] $\vec{r}_{r}=\frac{n_{i}}{n_{r}} \vec{r}_{i}-\left(\frac{n_{i}}{n_{r}}\left(\overrightarrow{r_{i}} \cdot \vec{n}\right)+\sqrt{1-\left(\frac{n_{i}}{n_{r}}\right)^{2}\left(1-\left(\overrightarrow{r_{i}} \cdot \vec{n}\right)^{2}\right)}\right) \vec{n}$

where,

$n_{i}, n_{r}=$ media refraction indices before and after refraction,

$\vec{r}_{i} \quad=$ unit vector of the optical ray before refraction (incident ray),

$\vec{r}_{r} \quad=$ unit vector of the optical ray after refraction (refracted ray), and

$\vec{n} \quad=$ normal vector at the refraction interface.

For the photogrammetry-based method, it was assumed that the thickness of the acrylic wall was uniform and remains constant under pressure. Consequently, the inner surface of the acrylic cell can be easily determined by redefine $C$ in equation [2] as $(\sqrt{C}-t)^{2}$. With the known intercept point $D$, the direction of the refracted ray $\vec{r}_{r}$, and inner surface of the acrylic cell, the intercept point $C$ of the refracted ray at the inner surface of the acrylic cell can be solved. The normal of the inner surface of the acrylic cell at point $C$ can also be calculated in a similar way to that at point $D$. Then, the Snell's law can be applied again to determine the optical ray $C P$ after the refraction at the cell-water interface.

The same optical ray tracing process can be applied to image points $I_{l}$ through $I_{n}$ in multiple images for the same point $P$ at the soil surface as shown in Fig. 3(a). If there is no error, all the tracing lines $C_{1} P, C P$, and $C_{n} P$ will converge to the same point $P$ and only two tracing rays are sufficient to obtain the intersection point $P$. However, errors unavoidably exist in the measurement and computational processes and it is very likely for lines $C_{1} P, C P$, and $C_{n} P$ to be 
$C_{1} P_{1}, C P$, and $C_{n} P_{n}$ in the $3 \mathrm{D}$ space as shown in Fig. 3(c). Therefore, a least-square optimization technique was used to best-estimate the $3 \mathrm{D}$ coordinates of point $P$. It was postulated that if the sum of square of a point $P$ 's distances to all the tracing rays is the minimal, the point is the light source where all the rays are generated. Mathematically, the process to find the "true" location of the object point is to find a combination of $\left(X_{P}, Y_{P}, Z_{P}\right)$ which can minimize the following equation:

$$
d_{\text {total }}=\sum_{i=1}^{n} d_{i}^{2}, d_{i}^{2}=\left(X_{P}-X_{C_{i}}\right)^{2}+\left(Y_{P}-Y_{C_{i}}\right)^{2}+\left(Z_{P}-Z_{C_{i}}\right)^{2}-\left(\left(X_{P}-X_{C_{i}}\right) \alpha_{r 2 i}+\left(Y_{P}-Y_{C_{i}}\right) \beta_{r 2 i}+\left(Z_{P}-Z_{C_{i}}\right) \gamma_{r 2 i}\right)^{2}
$$

where,

$$
\begin{aligned}
d_{i}= & \text { distance between the estimated point position } P \text { and the corresponding } \\
& \text { optical ray, }
\end{aligned}
$$

$X_{P}, Y_{P}, Z_{P} \quad=\quad 3 \mathrm{D}$ coordinates of the estimated point position $P$ in the global coordinate system,

$X_{C_{i}}, Y_{C_{i}}, Z_{C_{i}}=3 \mathrm{D}$ coordinates of the intercept point $C$ at the inner surface of the acrylic cell wall in the global coordinate system, and

$\alpha_{r 2 i}, \beta_{r 2 i}$, and $\gamma_{r 2 i}=\quad$ direction cosine of the corresponding optical ray $C P$ in the global coordinate system.

To use the least-square method for the best-estimation of point position, at least two optical rays for the same point on the specimen surface are required. The same optical ray tracing and least-square estimation processes could be performed to all points of interest on the specimen surface to obtain their 3D coordinates. With the 3D positions of these points, full-field deformation of the soil specimen during triaxial testing can be derived, which will be discussed in the following sections. 


\section{Measurement Procedure}

The procedure of the photogrammetry-based method for deformation measurement on a saturated or unsaturated soil during triaxial testing is presented as follows:

- Camera Calibration: The principle of photogrammetry is based on the pinhole camera model. To be treated as a pinhole camera, the used camera is required to be calibrated first to determine its internal characteristics such as lens focal length, perspective center (as shown in Fig. 3), image sensor resolution, and some distortion parameters. A typical calibration result for the used camera is presented in Table 1. More explanations regarding the calibration process can be found in Zhang et al. (2015).

- System Setup: The soil specimen is installed in the triaxial cell by following the normal procedures for soil triaxial testing. In addition to this, measurement targets are attached to the test specimen, acrylic cell wall, and the load frame during the installation process.

- Photographing: After system setup, images around the testing system are captured following a pattern as shown in Fig. 2(c). During image capturing, the aperture is set to a small opening (e.g. F-number of 10) to increase the depth of field which allows the whole specimen to appear in focus. To ensure a proper light exposure, the built-in flash of the camera is set on. To reconstruct a full 3D model of a cylindrical specimen during triaxial testing with the system setup shown in Fig. 2(b), a typical number of 22 images with overlaps are sufficient as shown in Fig. 2(c). Five images are taken from positions far away from the testing system to capture the whole testing system with load frame (CS1 to CS5 in the form of a cross, a typical image is shown in Fig. 2(b)). The other 17 images (CS6 to CS22 in Fig. 2(c) from different view angles, a typical image is shown in Fig. 2(d)) are taken at positions closer to the triaxial testing system to have a better view to a specific part of the specimen surface. More images are definitely 
beneficial to improve the accuracy of the measurements. However, the associated computational efforts will increase accordingly.

- Photogrammetric Analysis: Before photogrammetric analysis, all images are idealized. Distortions due to the used lens are eliminated for the idealized images which are considered as captured by a pinhole camera. Then, a photogrammetric analysis is performed to determine the orientations of the camera stations and the $3 \mathrm{D}$ positions of the measurement targets on the load frame and acrylic cell as shown in Fig. 2(c). During the photogrammetric analysis, only the measurement targets in the air (i.e., targets on the load frame and acrylic cell) are used. The measurement targets on the soil specimen surface must not be involved due to refraction effects at the interfaces of the air-acrylic cell and acrylic cell-water. It is suggested that the same global coordinate system as shown in Fig. 2(c), which is set on the load frame, should be utilized for different measurements to facilitate further deformation analyses and comparisons.

- Acrylic Cell Reconstruction: To facilitate the optical ray tracing process, the barrelshaped outer and inner cell surfaces, which are two interfaces for refraction correction, is required to be reconstructed using eq. [2] based on the 3D coordinates of measurement targets on cell wall surface. The cell wall reconstruction is to find the best combination of nine parameters (i.e. $\left.A, B, C, X_{R}, Y_{R}, Z_{R}, \kappa^{\prime}, \omega^{\prime}, \varphi^{\prime}\right)$ which can minimize the distances between the targets on cell wall surface and the reconstructed cell wall surface using the least-square method. With the thickness of the acrylic cell wall, the inner surface of the cell wall is also reconstructed.

- Optical Ray Tracing: To determine the 3D position of a measurement target on the specimen surface, optical rays from the corresponding camera stations are constructed and traced from each corresponding camera station to the specimen surface using the Snell's law as shown 
in Fig. 3. After ray tracing process, optical rays as well as their start points at the inner surface of the acrylic cell are determined.

- 3D Coordinates Estimation: The optical ray tracing and least square-estimation processes are then repeated for all targets on the soil surface to construct the full 3D model of the soil specimen.

\section{POST-PROCESSING}

\section{Accuracy Self-check}

For the conventional image-based methods (Bhandari et al. 2012; Gachet et al. 2007; Lin and Penumadu 2006; White et al. 2005; Desrues 2004; and Macari et al. 1997), a sophisticated system calibration is required due to difficulties in dealing with refractions at the air-cell and cell-water interfaces. This system calibration can be unreliable when there are variations in ambient temperature and chamber pressure. However, for the newly developed photogrammetrybased method, the system calibration is not necessary and the measurement accuracy can be selfchecked. For a specific photogrammetry-based measurement, using the setup in Fig. 2(b) as an example, after a photogrammetry analysis on the captured 22 images, all the 3D positions of measurement targets on cell wall surface are determined as shown in Fig. 4(a).

For a specific point 93 at specimen surface as shown in Fig. 2(b) and 2(d), an optical ray tracing process was then performed as typically shown in Fig. 4(a). Since point 93 was found on images captured at camera stations of $8,9,11,12$, and 13 , five corresponding optical rays were constructed from their camera stations to the triaxial cell surface. At the outer surface of the triaxial chamber, optical rays bent at different intercept points and then intercepted with the inner surface of the triaxial cell wall. Directions of five optical rays changed again at the inner surface 
of the triaxial cell wall and then reached point 93 as shown in Fig. 4(a). Fig. 4(b) shows an enlargement of five optical rays near point 93. These optical rays are lines in the 3D space without a common intercept point. As shown in Fig. 4(b), the least-square method is then used to estimate the 3D position of point 93 as summarized in Table 2. It is found that the distances between these optical rays and the estimated point 93 varied from 0.012 to $0.226 \mathrm{~mm}$ with an average of $0.07 \mathrm{~mm}$. The same procedure was applied to all the other points and a 3D model of the specimen surface inside the triaxial chamber is constructed as shown in Fig. 4(a). Theoretically, as addressed before, with two of optical rays after the refraction at the cell-water interface, the 3D position of a measurement target on the specimen surface can be determined. The distance $d_{i}$ between the estimated point and any other corresponding optical ray was a selfcheck of the measurement accuracy. The average of the distances $d_{i}$ could be considered as a proper indicator of the measurement accuracy. In this study, if the average $d_{i}$ was below $0.1 \mathrm{~mm}$, the measurement was considered to be accurate. Subsequently, for $d_{i}$ values greater than 0.15 $\mathrm{mm}$, the corresponding optical rays were deleted due to "poor" accuracy. Least-square estimation was performed again without the deleted rays to further improve the measurement accuracy. For example, at point 93 , the $d_{i}(0.226 \mathrm{~mm})$ between the estimated point and optical ray from camera station 8 was deleted which reduced the total number of optical rays from five to four as shown in Fig. 4(c). Subsequently, the least-square estimation was reprocessed. As summarized in Table 2 , it is found that the $d_{i}$ between the estimated point of 93 and four optical rays vary from 0 to $0.034 \mathrm{~mm}$ which further reduced the average $d_{i}$ to $0.023 \mathrm{~mm}$. For the photogrammetry-based method, the accuracy self-check characteristic is quite unique when compared to the conventional image-based methods. 


\section{Volume Calculation}

With the 3D coordinates of the measurement targets on the soil surface, a typical point cloud was plotted in a 3D space as shown in Fig. 5(a) for the specimen before any deformation. To facilitate further deformation analysis, an enclosed triangular surface mesh was then generated as shown in Fig. 5(b). To calculate the total volume, an arbitrary point $P_{o}$ was added inside of the 3D model of the specimen. By connecting this point with each point on the enclosed 3D surface, a series of tetrahedrons $P_{o} P_{1 i} P_{2 i} P_{3 i}$ were created as typically shown in Fig. 5(c). The volume for each tetrahedron can be easily calculated based on the $3 \mathrm{D}$ coordinates of points $P_{o}, P_{1 i}, P_{2 i}$, and $P_{3 i}$ using eq. [5].

[5] $V=\sum_{i=1}^{n} v_{i}=\frac{1}{6} \sum_{i=1}^{n}\left|\overrightarrow{P_{o} P_{1 i}} \sqsubset\left(\overrightarrow{P_{o} P_{2 i}} \times \overrightarrow{P_{o} P_{3 i}}\right)\right|$

where $P_{o}, P_{1 i}, P_{2 i}$, and $P_{3 i}$ are four vertices of the $i^{\text {th }}$ tetrahedron as shown in Fig. 5(c).

The total volume of the space that the triangular mesh covered is the sum of the volumes of all tetrahedrons. This volume calculation method takes advantage of all the measurement targets on specimen surface without any assumption on specimen shape.

\section{Strain Calculation}

The soil surface deformation data can be used to evaluate the local displacement mechanisms leading to the triggering of the formation of persistent shear bands, the timing of shear band formation with regard to the achievement of peak stress, and the character of displacements within fully formed shear bands. Previously published data only covered part of the whole soil surface (Desrues and Viggiani 2004; Lin and Penumadu 2006; Rechenmacher 2006; and Bhandari et al. 2012). The photogrammetry-based method for the first time makes it possible to observe full-field deformation of soils during triaxial testing. 
With the 3D positions of the measurement targets on soil surface at different loading steps, full-field displacement and strain distributions can be extracted. Contour plots are commonly used for the visualization of displacement and strain of the soil during triaxial testing. However, similar to the other studies (Desrues and Viggiani 2004; Rechenmacher 2006; Lin and Penumadu 2006; Chupin et al. 2012; and Bhandari et al. 2012), only discrete displacement points on the specimen's surface can be obtained from the photogrammetry-based method. Interpolation is often used by most researchers to obtain the full-field contour plots of a specimen from discrete displacement points. To facilitate strain analysis, 3D coordinates of those measurement targets in the global coordinate system $(X-Y-Z)$ were transformed to a cylindrical $z-r-\theta$ coordinate system as shown in Fig. 5(c). The $z$-axis is set to be the center line of the soil cylinder and the origin of the cylindrical coordinate system was set to be at the bottom surface. The strain calculations were performed in this cylindrical coordinate system. In this paper, strain calculation and interpolation techniques similar to that presented in Lin and Penumadu (2006) were adopted to generate a continuous deformation field. Detailed strain calculation process is presented in the Appendix.

\section{TRIAXIAL TESTS ON AN UNSATURATED SOIL}

To evaluate the capabilities of the newly developed photogrammetry-based method, a series of undrained (constant water content) triaxial tests were performed for deformation characteristics investigation on unsaturated soils during triaxial testing. The tested material is a mixture of Fairbanks silt and Kaolin at a ratio of $85: 15$. Basic properties of the used soil are presented in Table 3. 


\section{Specimen Preparation}

The soil was oven-dried and mixed with water to the desired moisture content $(16 \%$ in this case). Then, the soil passed through a No. 16 sieve with an opening size of $1.19 \mathrm{~mm}$. The reason for sieving was that the mixture prepared before sieving was extremely heterogeneous and the size of each lump varied greatly from tiny packets to lumps more than $5 \mathrm{~mm}$ in diameter. The material remaining on the sieve was broken up and sieved once more with the whole process repeated until all material passed the sieve. The sieved soil was placed in a plastic bag and sealed with tape. The sealed plastic bag was kept in an air-tight container for at least 12 hours to allow the water content to equalize throughout the material. In order to achieve a uniform density throughout the specimen, soil was statically compacted in 10 layers in a split mold, which hosted a latex membrane, to $142 \mathrm{~mm}$ in height and $71 \mathrm{~mm}$ in diameter cylinders according to the method presented in Ladd (1978). The specimens were compressed at a constant rate of 1.5 $\mathrm{mm} / \mathrm{min}$ which is also used by Sivakumar (1993). During compaction, before adding another soil layer, the compacted soil surface was scratched to ensure good contact between adjacent soil layers. This process was repeated until a full specimen of $142 \mathrm{~mm}$ in height was achieved. After compaction, the split mold was detached and the membrane used to cover the soil cylinder was carefully removed. Then, the soil specimens were sealed in containers and conditioned to different moisture contents by controlling the number of exposures to atmosphere for 15 minutes/day. After that, the soil specimens were sealed in plastic bags and stored in a humidityand temperature-controlled environment for at least one month to ensure moisture equilibrium in the whole soil specimen. 


\section{Experimental Program}

A series of undrained triaxial tests, which included an isotropic loading-unloading-reloading process and a deviatoric loading-unloading-reloading process under different confining stresses, were conducted on the specimens with different moisture contents. According to Fredlund and Rahardjo (1993), it is difficult to maintain an undrained condition for the pore-air due to its ability to diffuse through the pore-water. So, for the undrained triaxial conducted in this study, the vent valve was open for air exchange during testing. The system setup for the triaxial tests is typically shown in Fig. 3(b). A total number of 108 measurement targets (approximately $5 \mathrm{~mm}$ in diameter) in 9 rows and 12 columns with a spacing of approximately $17 \mathrm{~mm}$ were posted to the membrane which covered the soil surface.

The loading process for each specimen was different from each other. For specimen A with water content of $13.49 \%$, the deviatoric load was applied under a $5 \mathrm{kPa}$ confining stress to failure and then to an axial displacement of $10 \mathrm{~mm}$. For specimens B with water content of $15.91 \%$, an isotropic loading process was performed first to a net confining stress of $200 \mathrm{kPa}$ and followed by a deviatoric loading stage to an axial displacement of $20 \mathrm{~mm}$. For specimens $\mathrm{C}$ and $\mathrm{D}$ with water contents of $13.20 \%$ and $15.57 \%$, an isotropic loading process was performed first to 300 $\mathrm{kPa}$ and unloaded to $150 \mathrm{kPa}$ and then reloaded to 400 and $600 \mathrm{kPa}$, respectively and followed by a deviatoric loading stage to an axial displacement of $20 \mathrm{~mm}$. Both isotropic and deviatoric loads were applied in steps during triaxial testing. After each load step, images were captured around the testing system for deformation measurement using the photogrammetry-based method. During the triaxial shearing stages, the applied deviatoric loads were recorded and presented in Fig. 6(a). 
For specimen A under $5 \mathrm{kPa}$ net confining stress, during deviatoric stage, soil failed and a deviatoric stress peak was observed at an axial strain of $3 \%$. However, for specimens $\mathrm{B}$, C, and D under confining stresses of $200 \mathrm{kPa}$ and higher, the applied deviatoric stress continuously increased with increasing axial strain till an axial displacement of $20 \mathrm{~mm}$. Fig. 6(b) presented the pictures of four specimens after the undrained triaxial testing. A clear shear band was identified on specimen A, which was sheared under a net confining stress of $5 \mathrm{kPa}$. However, specimens $\mathrm{B}$, C, and D turned into barrel-shaped after the deviatoric loading under high confining stresses.

\section{EXPERIMENTAL RESULTS}

\section{Volume Change}

In this study, with the 108 measurement targets on the soil surface, a triangular mesh as shown in Fig. 5(b) was generated which included 192 tetrahedrons connected to the side surface and 20 tetrahedrons connected to the top and bottom surfaces. Figs. 7(a) and 7(b) present the triangular meshes for specimens $\mathrm{A}$ and $\mathrm{C}$ during deviatoric loading at different axial displacement levels, respectively. Since the applied axial displacement was limited to $10 \mathrm{~mm}$, deformation of specimen A was not significant till the end of the test as shown in Fig. 7(a). However, as shown in Fig. 7(b), specimen $\mathrm{C}$ gradually turned into barrel-shaped during deviatoric loading which is consistent with Fig. 6(b).

Using the volume calculation method discussed before, soil specific volume changes during isotropic and deviatoric loadings were computed and presented in Figs. 8(a) and 8(b), respectively. During isotropic loading, as shown in Fig. 8(a), soil volumes decreased with increasing confining stress which is reasonable since the applied confining load compressed the unsaturated soils at different moisture contents. Similar volume change results during isotropic 
loading can also be found for triaxial tests on unsaturated soils under drained condition in previous studies (e.g. Wheeler and Sivakumar 1995; Rampino et al. 1999) in which the doublewall cell method was used for volume change measurements. The experimental data reported in Fig. 8(a) also shows the loading collapse behavior of the tested unsaturated soil when the applied isotropic load was greater than $150 \mathrm{kPa}$. When there was an isotropic unloading (i.e. decrease in net confining stress), the volume of the tested specimens not fully rebounded due to the elastoplasticity of unsaturated soils which is also consistent with the findings presented in Rampino et al. (1999) and Thu (2006). During deviatoric loading under different net confining stresses, as presented in Fig. 8(b), the unsaturated soil specimen underwent dilation throughout the deviator stage under $5 \mathrm{kPa}$ net confining stress. However, under higher confining stresses $(>=200 \mathrm{kPa})$, indicated by the slopes of the volumetric strain curves, the soil demonstrated contraction at the early age of deviatoric stage and then gradually stabilized (e.g. specimen B) or contraction till the end (e.g. specimens C and D) through a closer scrutiny of the volumetric verses axial strain curve. Similar volume change results during deviatoric loading at different confining stresses are also found for loose sand as presented in Desrues and Viggiani (2004).

\section{Volumetric Strain Non-uniformity}

In the past, for triaxial tests on both saturated and unsaturated soils, volumetric strain of a soil specimen during isotropic or deviatoric loading was usually assumed to be uniformly distributed in the whole specimen. The assumption of uniform volumetric strain might be the truth for a soil behavior under isotropic load. However, during triaxial testing, soil volumetric strain throughout the whole specimen might not be uniform due to the end effect. Till now, no research effort has been published on unsaturated soil volumetric non-uniformity investigation. The major reason 
for this is lack of a proper method for full-field deformation measurements on soils during triaxial testing. However, with the newly developed photogrammetry-based method, the difficulties in full-field deformation measurement on unsaturated soils during triaxial testing no longer exist.

Since there were nine rows of measurement targets on each specimen surface, to facilitate the volumetric strain non-uniformity analysis, soil specimens were divided into eight layers (layer 1 to layer 8 from the top to bottom as shown in Fig. 5(b)). For specimens B, C, and D, during isotropic loading, the overall volumetric strain variations and volumetric strain variations of each soil layer are plotted against applied net confining stresses as shown in Fig. 9. Similar results were found in Figs. 9(a), 9(b), and 9(c) for three specimens isotropically loaded 200, 400, and $600 \mathrm{kPa}$, respectively. Variations of the volumetric strain did exist under the same isotropic load level. The major reason for this variation is believed to be neither were materials truly homogeneous at the scale of a laboratory specimen, nor were boundary conditions perfect. For specimens $\mathrm{B}, \mathrm{C}$, and $\mathrm{D}$, the minimum volumetric strains are found at layers 1,1 , and 8 which were at the ends of three specimens, respectively. This is reasonable since the end friction constrained the adjacent soil layers from deforming in the radial direction. In general, the trend of the volumetric strain variation different soil layers was consistent with the corresponding overall volumetric strain.

Under deviatoric load, the volumetric strain variations in each layer of four specimens are plotted against axial strain as shown in Fig. 10. Soil volumetric strains at different layers significantly varied throughout the deviatoric stage. The volumetric strain variation in different soil layers was getting higher and higher with the increasing axial strain. At the same axial strain level, the highest volumetric strain (dilation) is found on specimen A during deviatoric loading at 
$5 \mathrm{kPa}$ confining stress as shown in Fig. 10(a). The overall volumetric strain for specimen A increased with increasing confining stress. However, in layer 8, soil volume decreased due to end effect during deviatoric loading which was in contrast to the overall volume change. The high dilations were found at soil layers 4 and 5 since these two layers were at the middle of the specimen which was free from end effect. For specimen B as show in Fig. 10(b), the overall soil volume experienced contraction and then gradually stabilized at the end of the deviatoric loading. However, soil at layers 4 and 5 at the middle of the specimen experienced shear contraction at the early age of deviatoric loading to dilation afterwards. The lowest volumetric strains were found at layers 1 and 8 due to end effect, which is consistent with the observation on the soil specimen after testing as shown in Fig. 6(b). The volumetric strain variations of specimens C, and D during deviatoric loading were very similar to that of specimen B as shown in Figs. 10(c) and 10(d). However, for soil layers 4 and 5, the transitions from contraction to dilation were "delayed" when compared with that of specimen B. This delay was attributed to the decreasing of the effective stress ratio.

Table 4 summarizes the volumetric strain information of four specimens at axial strain levels of $3.6 \%, 8.6 \%$, and $14.3 \%$ during deviatoric loading. At the same axial strain level, soil volumetric strains increased with increasing confining stress. The standard deviations of the volumetric strains in different layers of four specimens were getting less with increasing net confining stress which indicated that the soil volumetric strain was getting more uniform. Also, for four specimens, the maximum difference between volumetric strain of each layer and the corresponding overall volumetric strain generally decreased with increasing net confining stress during deviatoric loading. 


\section{Full-field Strain Distribution}

With the strain calculation method presented in the Appendix, the full-field strain distributions of four specimens during isotropic and deviatoric loading were extracted. Using specimen D as an example, Fig. 11 shows the full-field axial displacement, axial strain, and radial strain distributions during isotropic loading. Since the applied load was isotropic, theoretically, no strain localization was expected. However, as shown in Fig. 11, localized deformations were still found in both radial and axial strain distribution plots which were consistent with the volumetric strain results. Since the lower end of the soil specimen rested on the triaxial cell pedestal, no displacement was detected as shown in Fig. 11(a) which was reasonable. The top surface of the specimen was in direct contact with the load cell which was movable. As a result, the maximum displacement was found to be at the top end of the specimen. At both ends of the specimen, soil axial strains were higher than the middle part as shown in Fig. 11(b) which is consistent with that the soil volumetric strains in layers 1 and 7 are higher than the other layers as presented in Fig. 8(c). It is interested to note that, under the same isotropic load, radial strain was much greater than the axial strain when a comparison was made between Figs. 11(b) and 11(c). Also, the radial strain as shown Figs. 11(c) was not evenly distributed which indicated that soil deformation was not axisymmetric during isotropic loading. Besides the detailed axial and radial strain analyses, the overall axial and radial strains at different isotropic load levels for specimens B, C, and D were also computed and summarized in Table 5.

In Table 5, the overall radial strains of specimens $\mathrm{B}, \mathrm{C}$, and $\mathrm{D}$ were much higher than the associated axial strains under the same isotropic loading conditions which were consistent with the findings from Fig. 11. Also, the axial to radial strain ratios slightly varied for the tested specimens at low confining stress $(200 \mathrm{kPa}$, in Table 5). These axial to radial strain ratios 
generally decreased with the increase of the isotropic load at the early stage of the isotropic loading and then stabilized. The major reason for this phenomenon was attributed to the used static compaction method (Ladd 1978) for specimen preparation. In other words, the specimen prepared using this compaction method was anisotropic. As a result, soil behavior was anisotropic under isotropic load.

Fig. 12 presented the full-field axial displacement, axial and radial strain distributions of specimen $\mathrm{A}$ at different axial strain levels under a $5 \mathrm{kPa}$ net confining stress. According to Fig. 6(a), specimen A failed at an axial strain level of 3\% (4 $\mathrm{mm}$ axial displacement) during deviatoric stage. Failure of many engineering materials is characterized by the formation and propagation of zones of localized shear deformation. The most typical localized deformation observed in soils is linear shear banding. As shown in Fig. 12(a), at $6.5 \mathrm{~mm}$ displacement, which was after soil failure, no shear band was observed at the displacement distribution plot. At 10 mm displacement, a nearly undeformed portion of the specimen sliding over the lower portion created a clear shear band which was consistent with the observation on Fig. 6(b) after testing. As shown in Fig. 12(b), at $3 \mathrm{~mm}$ axial displacement, no shear band was observed. As the axial displacement became larger, concentration of strain in a local zone occurred because of actual non-uniformity of the mass and stiffness of the material. Fig. 12(b) more clearly illustrated the formation of the shear band. Localized strains were found on the axial strain contours at $6.5 \mathrm{~mm}$ axial displacement. With an increase of axial displacement, localized radial strain was getting more and more concentrated when reaching an axial displacement of $10 \mathrm{~mm}$. Also, the concentrated radial strain was found at the right side of the specimen as shown in Fig. 12(c). This was because of the presence of the failure plane which broke the soil specimen into two portions. 
The upper right portion was slide over the lower portion and resulted in the concentrated radial strain.

According to Fig. 6(b), specimens B, C, and D turned into barrel-shaped after deviatoric loading to an axial displacement of $20 \mathrm{~mm}$. Taking specimen $\mathrm{C}$ as an example, Fig. 13 presents the full-field axial displacement, axial and radial strain distributions at different axial strain levels during deviatoric loading. In Fig. 13(a), at the same height, the axial displacement was quite uniform. No shear band was observed on the axial displacement and axial contours which was consistent with the picture of the soil specimen as shown in Fig. 6(b). However, it was noted that some localized strain can still be found on the radial and axial strain contours (see Figs. 13(b) and 13(c)). The possible reason for the distorted strain contours was attributed to the applied deviatoric load was eccentric and the non-uniformity of the specimen.

\section{TIME AND COST EFFICIENCY}

Only a digital camera with a fixed focal length lens (total cost is $\$ 1100$ in this study) is required for the photogrammetry-based deformation measurement method. Before triaxial testing, the measurement targets were manually posted to the load frame, outer surface of the acrylic cell, and specimen surface which took approximately an hour in our case. However, the setup for those targets on the load frame and cell wall surface was only required to be performed once and would be kept for future testing. Measurement targets can be directly printed on latex membranes which could significantly reduce the time required for test preparation. During triaxial testing, for a single measurement (i.e. construct the 3D model of the specimen at a specific loading condition), only two minutes were required to capture the images around the testing system for the deformation measurement. The total time for processing the captured 
images (included image point idealization, orientation, cell wall reconstruction, optical ray tracing, and least-square estimation) for the photogrammetry-based measurement was dependent on numbers of the images and measurement targets on specimen surface. Image point idealization and orientation processes were performed using existing photogrammetry software which typically took approximately three minutes. A MatLab-based program was developed and utilized for the cell wall reconstruction, optical ray tracing, least-square estimation, and postprocessing (volume and strain calculations) which typically took approximately five minutes. In other words, a single measurement using the photogrammetry-based method (from image capturing to data post-processing) could be completed in approximately 10 minutes.

\section{DISCUSSIONS}

The newly developed photogrammetry-based method is also an image-based method. However, it is significantly different from the conventional image-based methods due to the following reasons: (1) The camera is calibrated in order to be treated as a pinhole camera and eliminate lens distortions. A calibrated camera is very critical and beneficial for measurement accuracy improvement; (2) For system setup, the photogrammetry-based method only requires attaching some measurement targets on the load frame, triaxial cell wall, and specimen surface. However, for the system setup of the conventional image-based methods, great care and attention are required on the orientations and relative positions of the triaxial chamber and soil specimen to the camera station; (3) During image capturing, the camera is hand hold instead of mounted on a tripod in the conventional image-based methods which offers a great flexibility for image capturing. With this flexibility, images can be captured at any arbitrary distances and view angles to achieve the best measurement accuracy. During image capturing, no external lighting is 
required as long as the built-in flash of the camera is functional which is also different from the conventional image-based methods; (4) Principle of photogrammetry is adopted to accurately determine camera orientations where images are captured and shape and orientation of the triaxial chamber at different loading conditions. However, in the conventional image-based methods, the positions and orientations of the camera and cell wall are manually controlled. In the other words, the relative positions of the camera and cell wall might not be accurate; (5) Triaxial cell is assumed to be barrel-shaped which is consistent with the real shape of the triaxial chamber especially under a high chamber pressure. Also, the deformation of the cell wall under different chamber pressures were detected by photogrammetry instead of being neglected in the conventional image-based methods; (6) The Snell's law is adopted to correct refractions at the interfaces of the air-cell and cell-water in an arbitrary 3D coordinate system instead of in an idealized 2D coordinate system which offers great flexibility for refraction correction. In other words, optical rays can be traced from different randomly distributed camera stations to the soil surface in the triaxial cell. All assumptions in the conventional image-based methods are no longer required in the photogrammetry-based method; (7) In this study, approximately five images, instead of one for the conventional image-based methods, were utilized to determine the 3D position of a single measurement target on specimen surface. With no doubt, using more images is beneficial for the measurement accuracy improvement; (8) For the photogrammetrybased method, no system calibration is required before any measurement. Most importantly, the accuracy of the photogrammetry-based method can be self-checked by the $d_{i}$ values. However, for the conventional image-based methods, a sophisticated system calibration must be performed first before being used for any deformation measurement; and (9) With images captured all around the triaxial chamber, the full-field deformation of the soil specimen can be detected 
during triaxial testing. With this deformation, full-field strain distributions could be extracted for in-depth soil behavior analysis. However, in the conventional image-based methods, only part of the specimen deformation could be captured.

\section{CONCLUSIONS}

A non-contact photogrammetry-based method, which is significantly different from the conventional image-based methods, is presented to measure the deformation of unsaturated soils during triaxial testing. With this method, the conventional triaxial test apparatus for saturated soils can be used for triaxial testing on unsaturated soils without any modification. The proposed photogrammetry-based method is accurate, time- and cost-effective, requires only a digital camera to capture images of the soil specimen during triaxial testing from which accurate fullfield 3D models of the soil specimen at different loading steps are reconstructed. Most importantly, the accuracy of the photogrammetry-based method can be self-checked by the $d_{i}$ values. Another advantage of the photogrammetry-based method is that it can be utilized for deformation measurements on both saturated and unsaturated soils during triaxial testing with the same system setup.

A series of undrained triaxial tests on unsaturated soils was performed during which soil deformations were measured using the photogrammetry-based method. It was found that the photogrammetry-based method was capable of capturing soil deformation characteristics such as volume change, volumetric strain non-uniformity, barreling, full-field strain distribution, and shear band evolution. Based upon the measurement results, soil deformation was found to be not uniformly distributed during isotropic loading. The radial strain was nearly twice of the axial strain. Also, volumetric strains in different soil layers were not uniformly distributed during 
isotropic loading. During deviatoric loading, soil volumetric strains at different layers exhibited significant variation. Due to end effect, soil specimens gradually turned into barrel-shaped during deviatoric loading under confining stresses greater $200 \mathrm{kPa}$. Maximum volumetric strains were always found to be at the middle of the specimens. In addition, during deviatoric loading at $5 \mathrm{kPa}$ net confining stress, a clear shear band evolution process was captured based upon the deformation analysis results. Based upon the measurement results on the tested unsaturated soils, it could be concluded that the photogrammetry-based method is a powerful tool for in-depth soil deformation measurements during triaxial testing.

\section{REFERENCES}

Adams, B.A., Wulfsohn, D., and Fredlund, D.G. 1996. Air volume change measurement in unsaturated soil testing using a digital pressure-volume controller. ASTM Geotechnical Testing Journal, 19(1): 12-21.

Alshibli, K.A., Sture, S., Costes, N.C., Frank, M.L., Lankton, M.R., Batiste, S.N., and Swanson, R.A. 2000. Assessment of local deformation in sand using X-ray computed tomography. ASTM Geotechnical Testing Journal, 23(3): 274-299.

Bhandari, A.R., Powrie, W., and Harkness, R.M. 2012. A digital image-based deformation measurement system for triaxial tests, ASTM Geotechnical Testing Journal, 35(2): 209-226.

Bishop, A. and Donald, I. 1961. The experimental study of partly saturated soil in the triaxial apparatus. In Proceedings of the 5th international conference on soil mechanics and foundation engineering, Paris, July 17-22, 1:13-21. 
Chupin, O.A., Rechenmacher, L., and Abedi, S. 2012. Finite strain analysis of nonuniform deformation inside shear bands in sands. International Journal for Numerical and Analytical Methods in Geomechanics, 36(14): 1651-1666.

Clayton CRI, Khatrush SA 1986 A New Device for Measuring Local Axial Strains on Triaxial Specimens. Géotechnique, 36(4): 593-597.

Clayton CRI, Khatrush SA, Bica AVD, Siddique A. 1989. The use of Hall effect semiconductors in geotechnical instrumentation. ASTM Geotechnical Testing Journal, 12(1): 69-76.

Cui, Y. and Delage, P. 1996. Yielding and plastic behavior of an unsaturated compacted silt, Géotechnique, 46(2): 291-311.

Desrues, J. 2004. Tracking strain localization in geomaterials using computerized tomography. X-ray CT for Geomaterials: 15-41.

Desrues, J., and Viggiani, G. 2004. Strain localization in sand: an overview of the experimental results obtained in Grenoble using stereophotogrammetry. International Journal for Numerical and Analytical Methods in Geomechanics, 28(4): 279-321.

Fredlund, D. G., and Rahardjo, H. 1993. Soil Mechanics for Unsaturated Soils. New York: John Wiley and Sons, ISBN: 978-0-471-85008-3.

Gachet, P., Geiser, F., Laloui, L., and Vulliet, L. 2007. Automated digital image processing for volume change measurement in triaxial cells. ASTM Geotechnical Testing Journal, 30(2), 98-103.

GDS (2009): http://www.gdsinstruments.com/_assets_/products/000013/UNSAT_Datasheet.pdf, January 28. 2009. 
Geiser F. 1999. Comportément mécanique d'um limon non saturé: étude expérimentale et modélisation constitutive. Ph.D. thesis, Swiss Federal Institute of Technology, Lausanne, Switzerland.

Geiser, F., Laloui, L., Vulliet, L., Rahardjo, H., Toll, D., and Leong, E. 2000. On the volume measurement in unsaturated triaxial test. In Unsaturated soils for Asia. Proceedings of the Asian Conference on Unsaturated Soils, UNSAT-Asia 2000, Singapore, May 18-19, pp. 669674.

Hoyos, L. R., Laloui, L., and Vassallo, R. 2009. Mechanical testing in unsaturated soils. In Laboratory and Field Testing of Unsaturated Soils, pp. 63-77. Springer Netherlands.

Ladd, R. S. 1978. Preparing Test Specimens Using Under compaction. ASTM Geotechnical Testing Journal, 1(1): 16-23.

Laloui L, Pe'ron H, Geiser F, Rifa'i A, and Vulliet L 2006. Advances in volume measurement in unsaturated triaxial tests. Soils and Foundations, 46(3): 341-349.

Laudahn, A., Sosna, K., and Bohdp, J. 2005. A simple method for air volume change measurement in triaxial tests, ASTM Geotechnical Testing Journal, 28(3): 313-318.

Lin, H. and Penumadu, D. 2006. Strain localization in combined axial-torsional testing on kaolin clay, Journal of Engineering Mechanics, 132(5): 555-564.

Macari, E.J., Parken, J., and Costes, N.C. 1997. Measurement of volume changes in triaxial tests using digital imaging techniques, ASTM Geotechnical Testing Journal, 20(1): 103-109.

Mikhail, E.M., Bethel, J.S., and McGlone, J.C. 2001. Introduction to modern photogrammetry. Wiley. New York. ISBN 0-471-30924-9.

Ng, C.W., Zhan, L., and Cui, Y. 2002. A new simple system for measuring volume changes in unsaturated soils, Canadian Geotechnical Journal, 39(3): 757-764. 
Parker, J. K. 1987. Image processing and analysis for the mechanics of granular materials experiment. In ASME Proceedings of the 19th SE Symposium on System Theory, Nashville.

Rampino C, Mancuso C, Vinale F 1999. Laboratory testing on an unsaturated soil: equipment, procedures, and first experimental results. Canadian Geotechnical Journal, 36(1):1-12.

Rechenmacher, A. L. 2006. Grain-scale processes governing shear band initiation and evolution in sands. Journal of the Mechanics and Physics of Solids, 54(1): 22-45.

Rechenmacher, A. L., and Medina-Cetina, Z. 2007. Calibration of soil constitutive models with spatially varying parameters. Journal of Geotechnical and Geoenvironmental Engineering, 133(12): 1567-1576.

Rechenmacher, A., and Saab, N. 2002. Digital image correlation (DIC) to evaluate progression and uniformity of shear bands in dilative sands. In 15th ASCE Engineering Mechanics Conference, Columbia University, NY. June 5.

Romero, E., Facio, J., Lloret, A., Gens, A., and Alonso, E. 1997. A new suction and temperature controlled triaxial apparatus. Proceedings of the 14th International Conference on Soil Mechanics and Foundation Engineering, Vol. 1, Hamburg, Germany, September 6-12, pp. 185-188.

Sachan, A., and Penumadu, D. 2007. Strain localization in solid cylindrical clay specimens using digital image analysis (DIA) technique. Soils and Foundations, 47(1): 67-78.

Sharma, R. S., Hong, L., and Singhal, S. 2006. Developments in measurement of volume change in triaxial testing of unsaturated soils. In Advances in Unsaturated Soil, Seepage, and Environmental Geotechnics, ASCE, pp. 93-101. doi: 10.1061/40860(192)8.

Sivakumar, V. 1993. A critical state framework for unsaturated soil. Ph.D thesis, University of Sheffield. 
Thu, M.T. 2006, Shear strength and volume change relationship for an unsaturated soil, Ph.D thesis, Nanyang Technological University.

Wheeler, S. 1988. The undrained shear strength of soils containing large gas bubbles, Géotechnique, 38(3): 399-413.

Wheeler, S. J., and Sivakumar, V. 1995. An elasto-plastic critical state framework for unsaturated soil. Géotechnique, 45(1), 35-53.

White, D., Randolph, M. F., and Thompson, B. 2005. An image-based deformation measurement system for the geotechnical centrifuge. International Journal of Physical Modelling in Geotechnics, 5(3): 1-12.

Zhang, X., Li, L., Chen, G., and Lytton, R.L. 2015. A photogrammetry-based method to measure total and local volume changes of unsaturated soils during triaxial testing. Acta Geotechnica, 10(1): 55-82. 


\section{APPENDIX}

\section{Strain Calculation}

A small tetrahedron $\mathrm{P}_{\mathrm{o}} \mathrm{P}_{1 \mathrm{i}} \mathrm{P}_{2 \mathrm{i}} \mathrm{P}_{3 \mathrm{i}}$ was separated from the specimen, as shown in Fig. 5(c), with three nodes $\left(\mathrm{P}_{1 i}, \mathrm{P}_{2 \mathrm{i}}\right.$, and $\left.\mathrm{P}_{3 \mathrm{i}}\right)$ on the specimen surface and the fourth node $\mathrm{P}_{\mathrm{o}}$ located on $\mathrm{z}$ axis. Any point within the element would have three displacement components: vertical displacement, $u_{1}$, radial displacement, $u_{2}$, and circumferential displacement, $u_{3}$. It was assumed that the displacement of any point within the element was a linear function of the coordinates $\mathrm{z}, r$ and $\theta$ as shown in eq. [6].

[6] $u_{i j}=\alpha_{i 1}+\alpha_{i 2} z+\alpha_{i 3} r+\alpha_{i 4} \theta$

where $\alpha_{i j}$ are constants to be determined. Eq. [6] should be satisfied at all four nodes of the element. Therefore, eq. [7] can be obtained which is in matrix format:

[7] $\left\{\begin{array}{l}u_{i 1} \\ u_{i 2} \\ u_{i 3} \\ u_{i 4}\end{array}\right\}=\left\{\begin{array}{llll}1 & z_{1} & r_{1} & \theta_{1} \\ 1 & z_{2} & r_{2} & \theta_{2} \\ 1 & z_{3} & r_{3} & \theta_{3} \\ 1 & z_{4} & r_{4} & \theta_{4}\end{array}\right\} \cdot\left\{\begin{array}{l}\alpha_{i 1} \\ \alpha_{i 2} \\ \alpha_{i 3} \\ \alpha_{i 4}\end{array}\right\}$

where $z_{i}$ and $r_{i}$ are coordinates at the nodes, while $u_{i j}(i=1$ to $3, j=1$ to 4$)$ are displacements at the $j^{\text {th }}$ node in an element. The constants $\alpha_{i j}$ can be obtained using eq. [7] with given nodal displacements, $u_{i j}$. In order to determine constants $\alpha_{i j}$, the coordinates at the four nodes must be known. However, only the displacement components of those nodes on the outer surface of the specimen are known. It is reasonable to assume:

[8] $\left\{\begin{array}{l}r_{4}=0 \\ z_{4}=\left(z_{1}+z_{2}+z_{3}\right) / 3 \\ \theta_{4}=\left(\theta_{1}+\theta_{2}+\theta_{3}\right) / 3\end{array}\right.$ 
After determination of the constants $\alpha_{i j}$, the continuous deformation field was known and the strain components can be calculated by using the following eq. [9]. The strain calculation is similar to that presented in Lin and Penumadu (2006).

$[9]\left\{\begin{array}{l}\varepsilon_{z} \\ \varepsilon_{r} \\ \varepsilon_{\theta} \\ \varepsilon_{r \theta} \\ \varepsilon_{r z} \\ \varepsilon_{\theta z}\end{array}\right\}=\left\{\begin{array}{l}\frac{\partial u_{1}}{\partial z} \\ \frac{\partial u_{2}}{\partial r} \\ \frac{u_{2}}{r} \\ \frac{1}{2}\left(\frac{\partial u_{3}}{\partial r}+\frac{\partial u_{3}}{r \partial \theta}-\frac{u_{3}}{r}\right) \\ \frac{1}{2}\left(\frac{\partial u_{1}}{\partial r}+\frac{\partial u_{2}}{\partial z}\right) \\ \frac{1}{2}\left(\frac{\partial u_{2}}{r \partial \theta}+\frac{\partial u_{3}}{\partial z}\right)\end{array}\right\}=\left\{\begin{array}{l}\alpha_{12} \\ \alpha_{23} \\ \frac{1}{r}\left(\alpha_{21}+\alpha_{22} z+\alpha_{23} r+\alpha_{24} \theta\right)+\frac{\alpha_{34}}{r} \\ \frac{1}{2 r}\left(\alpha_{24}-\alpha_{31}-\alpha_{32} z-\alpha_{34} \theta\right) \\ \frac{1}{2}\left(\alpha_{13}+\alpha_{22}\right) \\ \frac{1}{2}\left(\frac{\alpha_{14}}{r}+\alpha_{22}\right)\end{array}\right\}$ 


\section{LIST OF FIGURES}

$2 \quad$ Fig. 1. (a) Double-wall cell triaxial test apparatus (modified from Bishop and Donald 1961); (b) Image-based method (modified from Macari et al. 1997).

4 Fig. 2. (a) Camera and lens; (b) System setup (image captured at camera station 1); (c) Image capturing; and (d) Image captured at camera station 9.

6 Fig. 3. Principle of the photogrammetry-based method: (a) Schematic representation; (b) Optical ray tracing; and (c) Least-square estimation.

Fig. 4. (a) Optical ray tracing for point 93; (b) Estimation with the ray from CS8; and (c) Estimation without the ray from CS8.

10 Fig. 5. (a) Point cloud; (b) Enclosed 3D surface; and (c) Tetrahedron generation.

11 Fig. 6. (a) Stress strain curves under different confining stresses; (b) Specimens after tests.

12 Fig. 7. Soil deformations during deviatoric stage: (a) Specimen A (b) Specimen C.

13 Fig. 8. (a) Soil volume variations during isotropic loading; (b) Soil volume variations during deviatoric loading under constant confining stresses.

15 Fig. 9. Volumetric variations during isotropic loading: (a) Specimen B; (b) Specimen C; and (c) 16 Specimen D.

17 Fig. 10. Volumetric variations during deviatoric loading under different confining stresses: (a)

$$
\text { Specimen A; (b) Specimen B; (c) Specimen C; and (d) Specimen D. }
$$

19 Fig. 11. Full-field deformation of specimen D during isotropic loading: (a) Axial displacement;

(b) Axial strain; and (c) Radial strain.

21 Fig. 12. Full-field deformation of specimen A during deviatoric loading under a confining stress of $5 \mathrm{kPa}$ : (a) Axial displacement; (b) Axial strain; (c) Radial strain. 
23 Fig. 13. Full-field deformation of specimen $\mathrm{C}$ during deviatoric loading under a confining stress of $400 \mathrm{kPa}$ : (a) Axial displacement; (b) Axial strain; (c) Radial strain. 


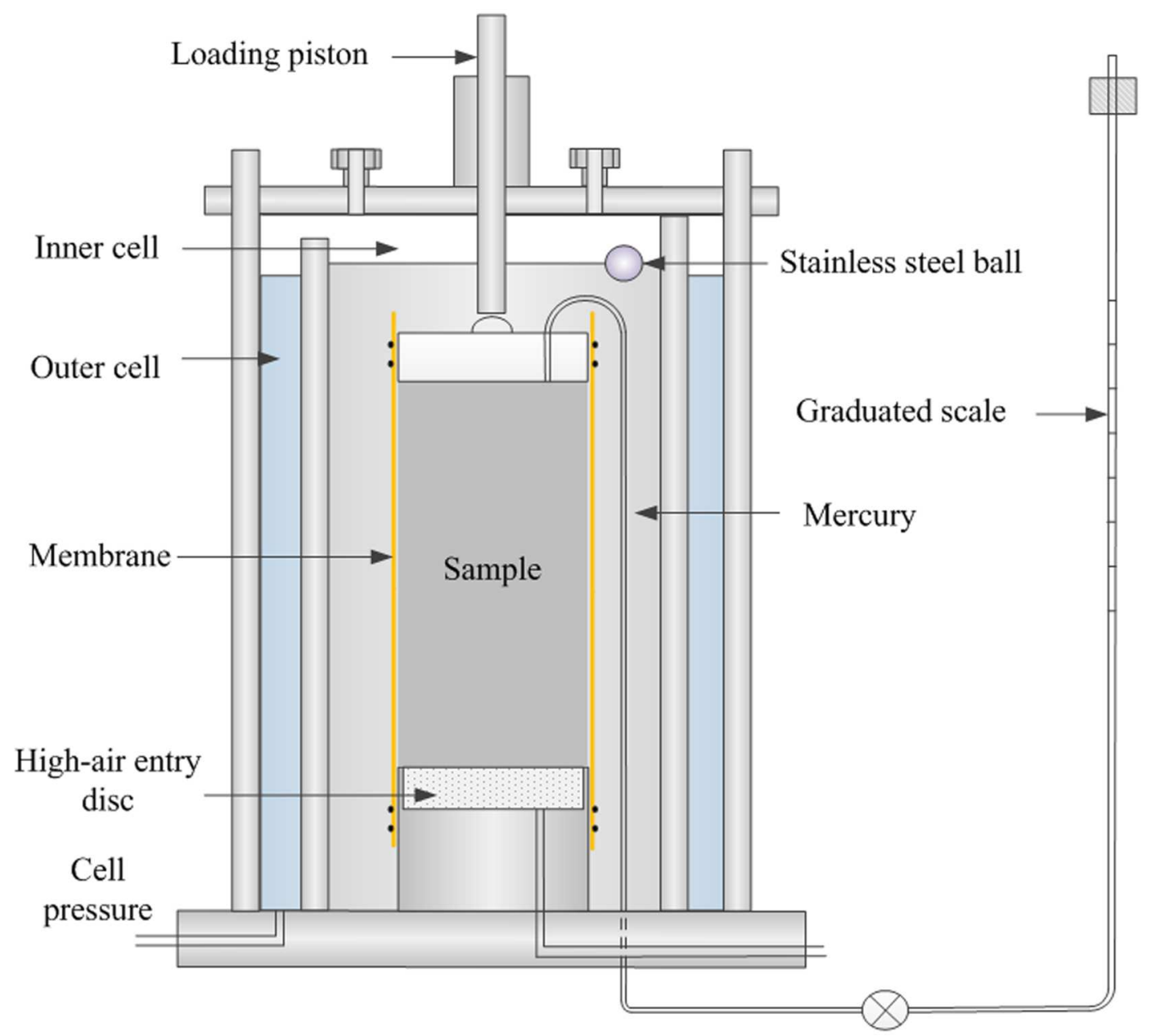

(a)

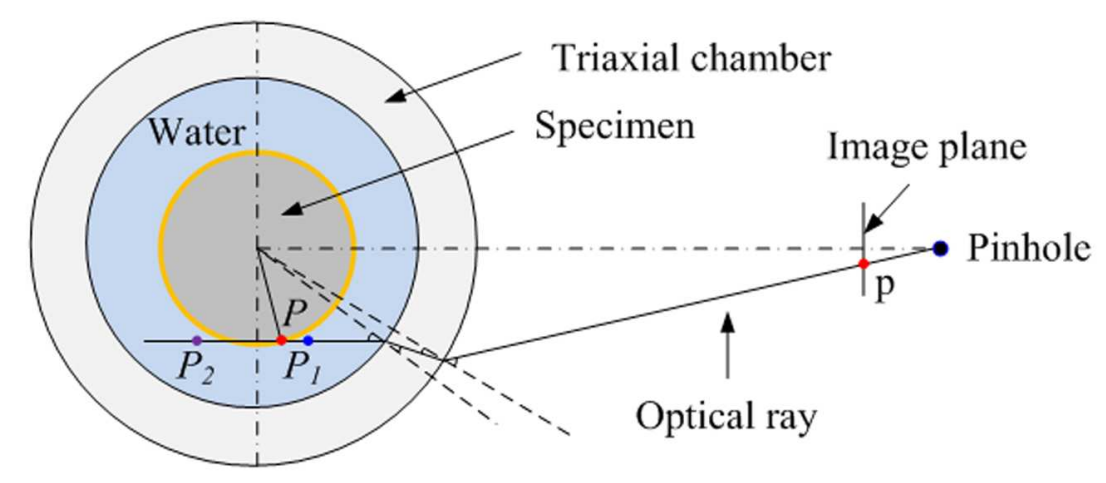

(b)

Fig. 1. (a) Double-wall cell triaxial test apparatus (modified from Bishop and Donald 1961); (b) Image-based method (modified from Macari et al. 1997). 


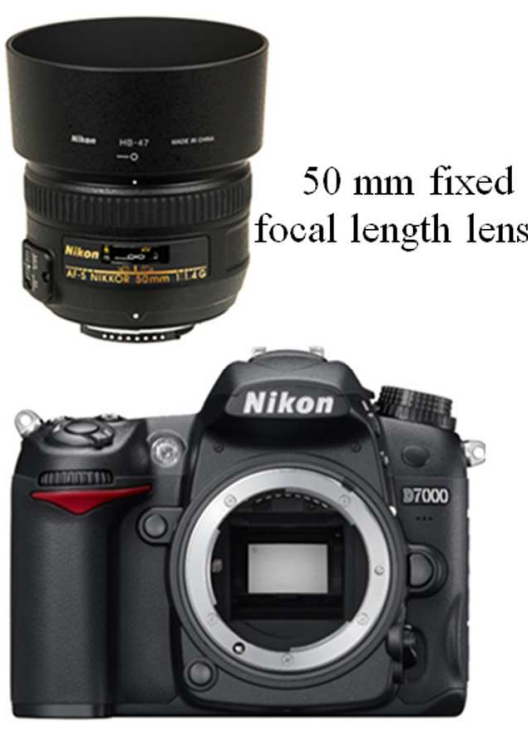

(a)

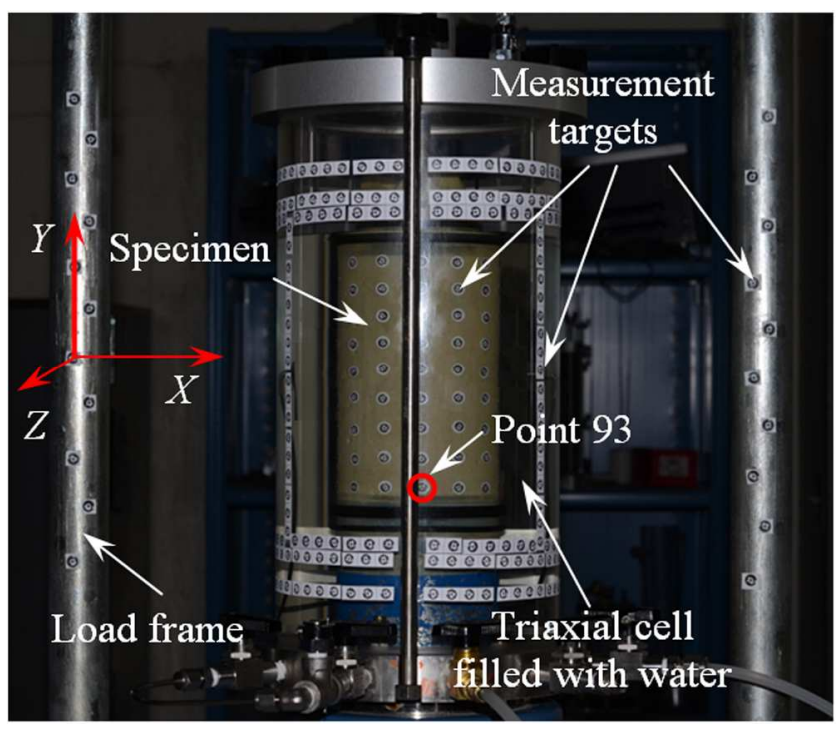

(b)

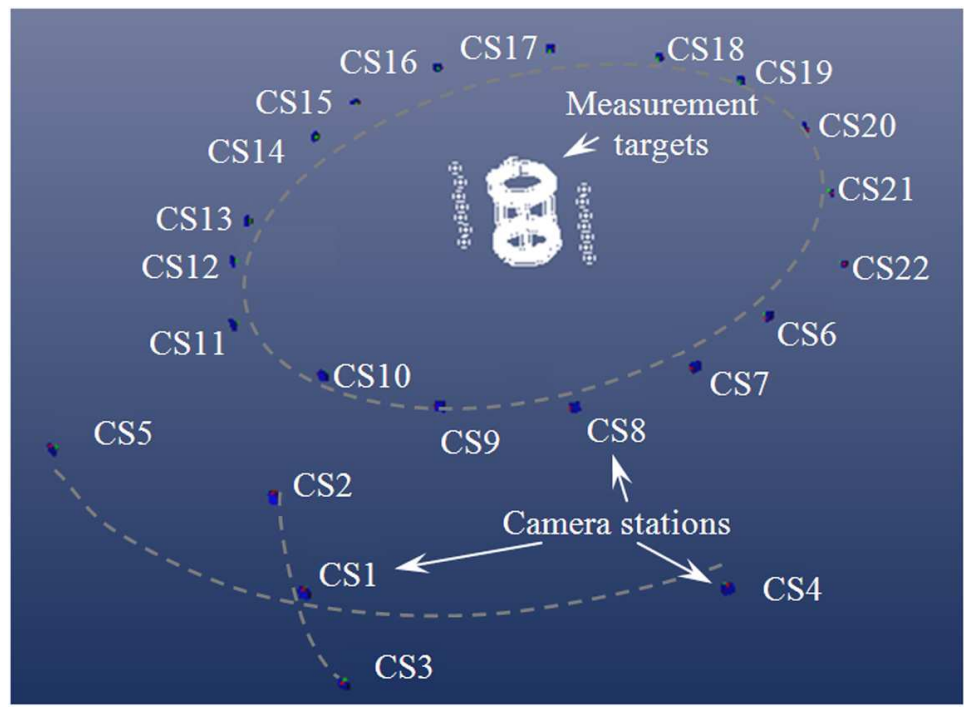

(c)

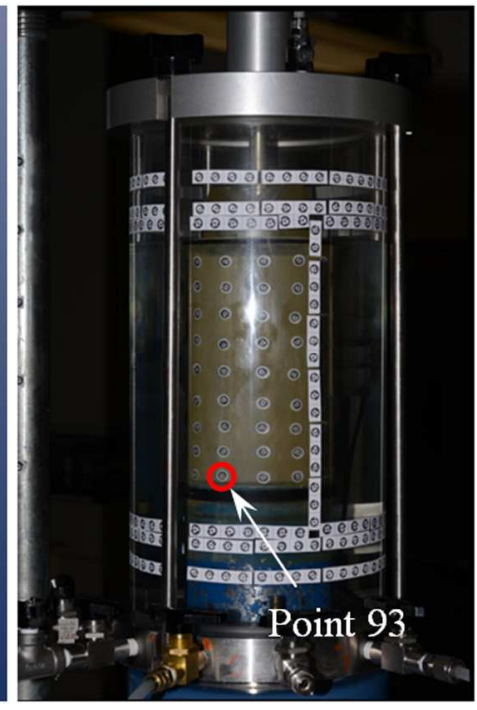

(d)

Fig. 2. (a) Camera and lens; (b) System setup (image captured at camera station 1); (c) Image capturing; and (d) Image captured at camera station 9. 


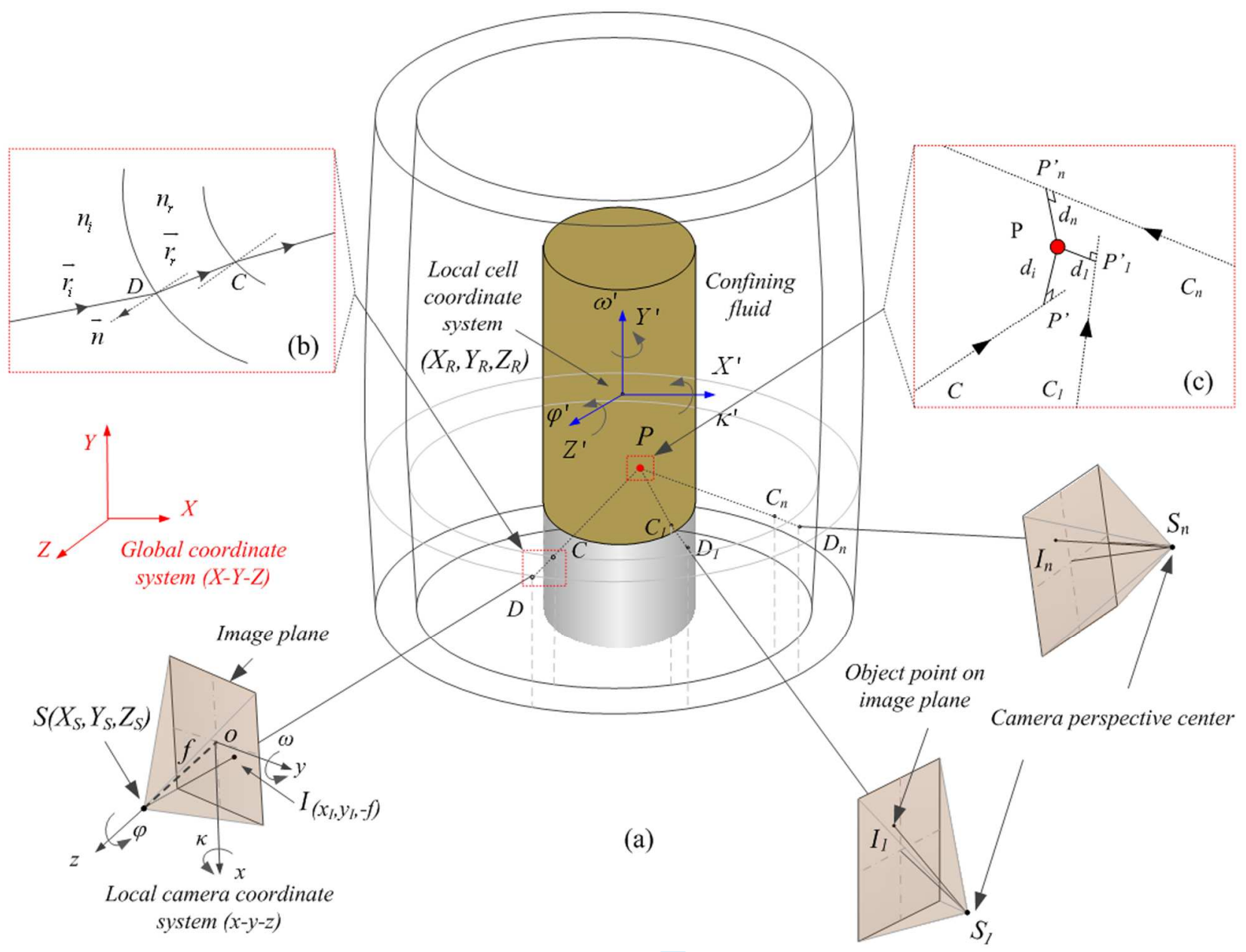

Fig. 3. Principle of the photogrammetry-based method: (a) Schematic representation; (b) Optical ray tracing; and (c) Least-square estimation. 


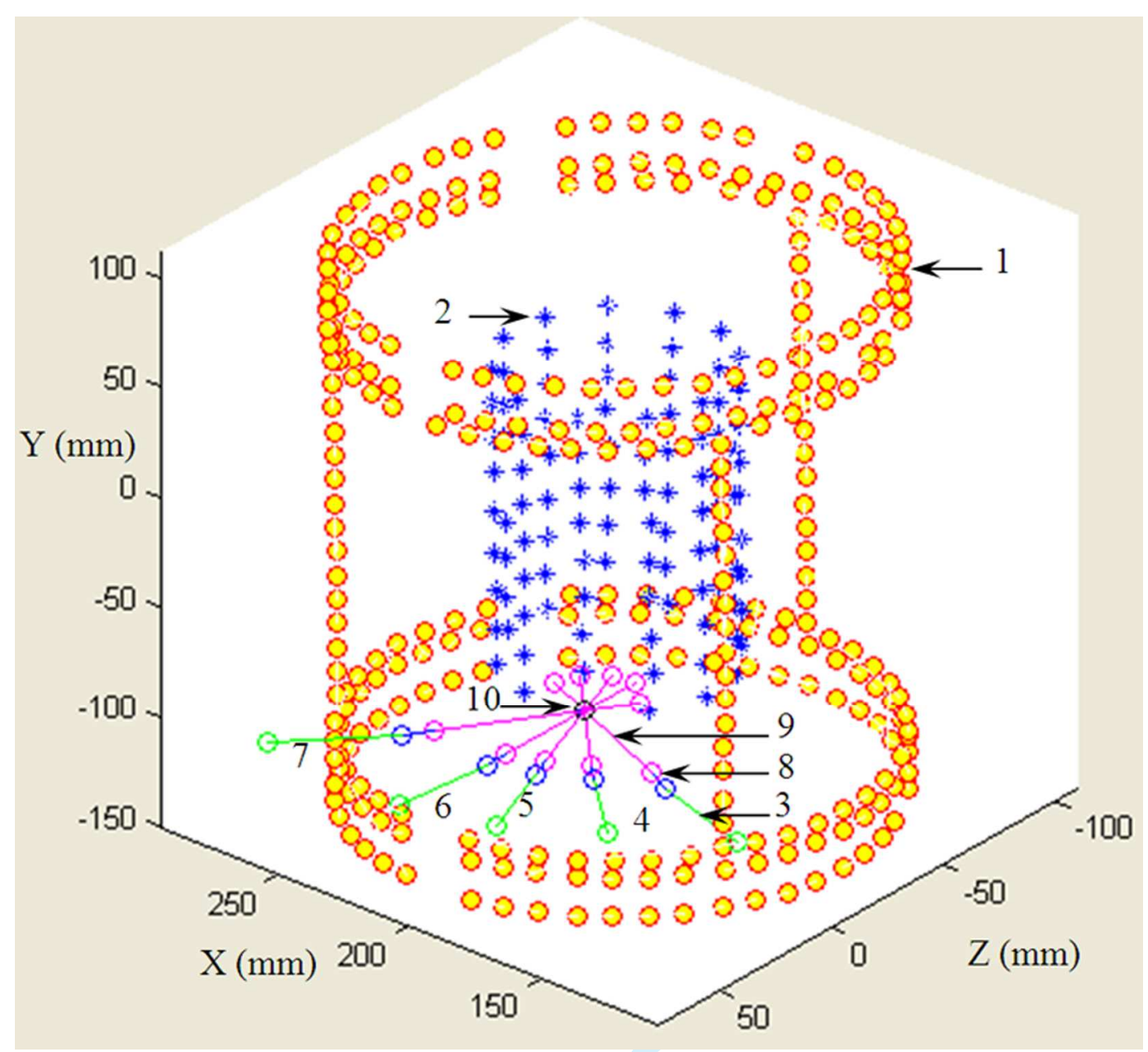

42 1. Measurement targets on cell wall; 2. Measurement targets on specimen surface; 3 . Optical ray 43 from CS 8; 4. Optical ray from CS 9; 5. Optical ray from CS 11;6. Optical ray from CS 12; 7. 44 Optical ray from CS $13 ; 8$. Optical ray in the triaxial cell wall; 9. Optical ray in the triaxial chamber; and 10. Point 93. 


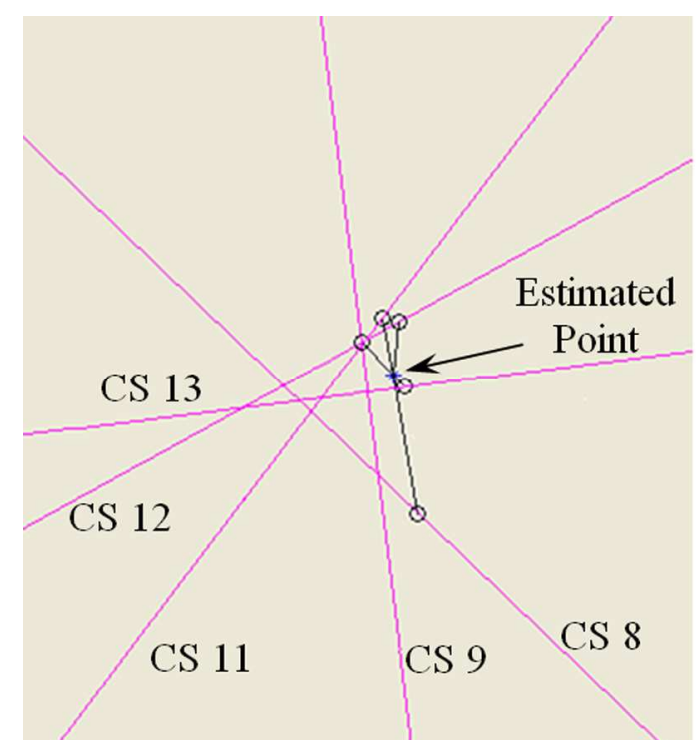

(b)

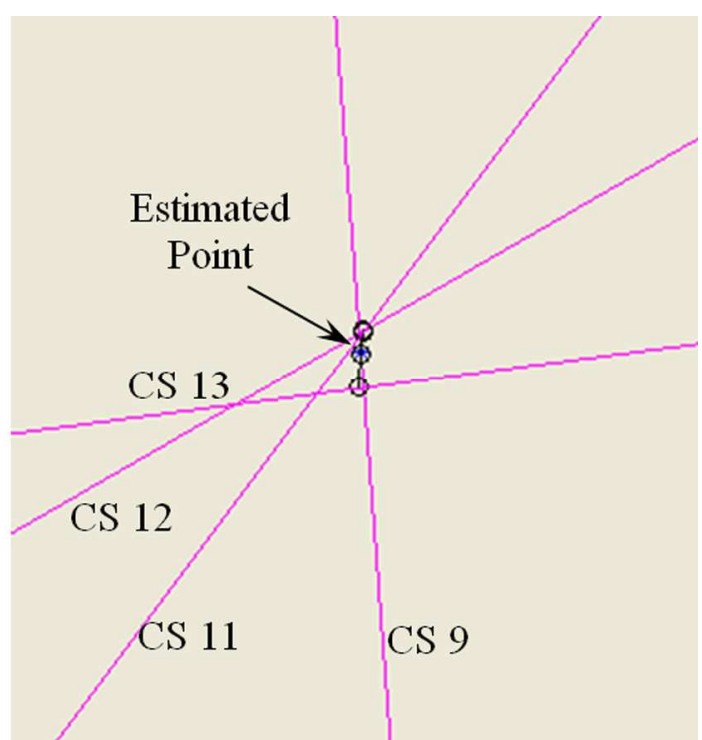

(c)

$50 \quad$ Fig. 4. (a) Optical ray tracing for point 93; (b) Estimation with the ray from CS8; and (c) 51 Estimation without the ray from CS8. 

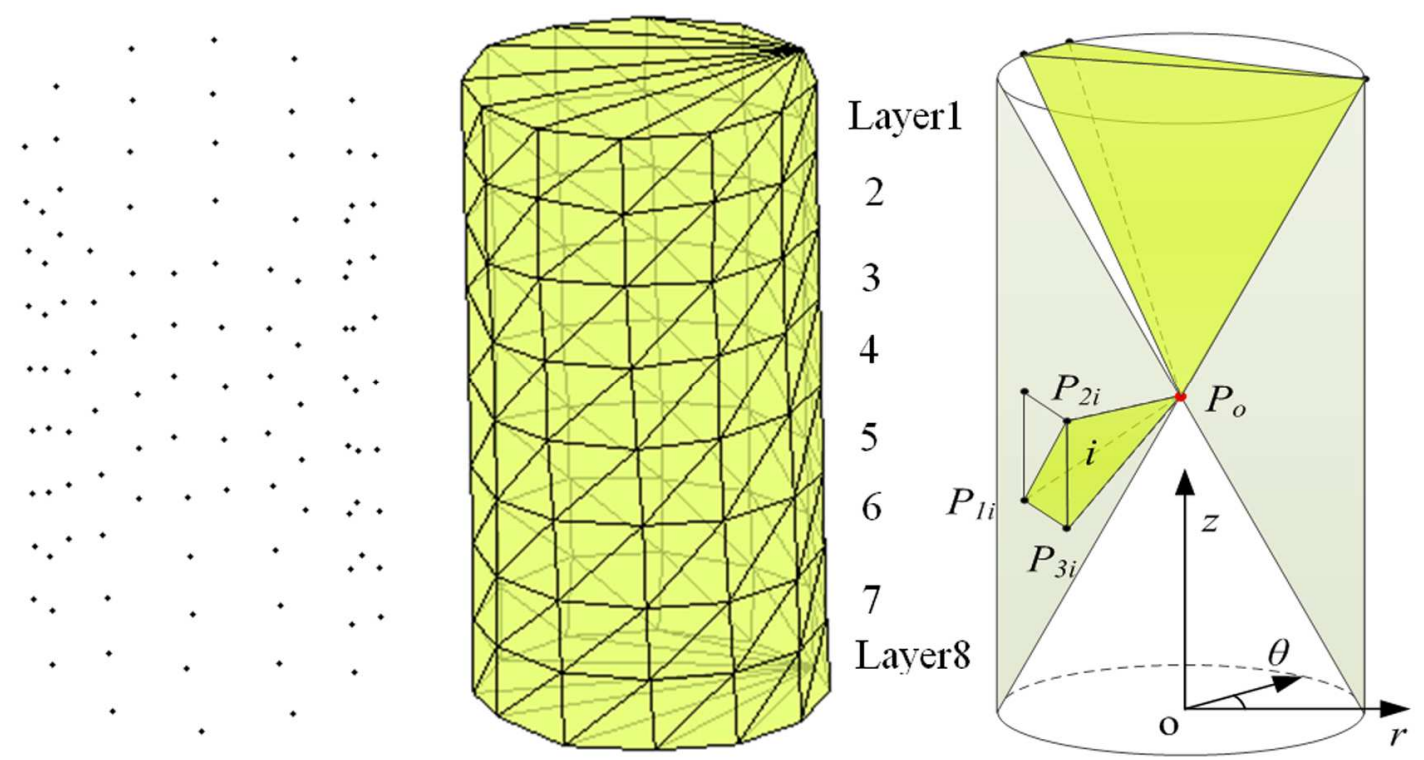

(a)

(b)

(c)

Fig. 5. (a) Point cloud; (b) Enclosed 3D surface; and (c) Tetrahedron generation. 


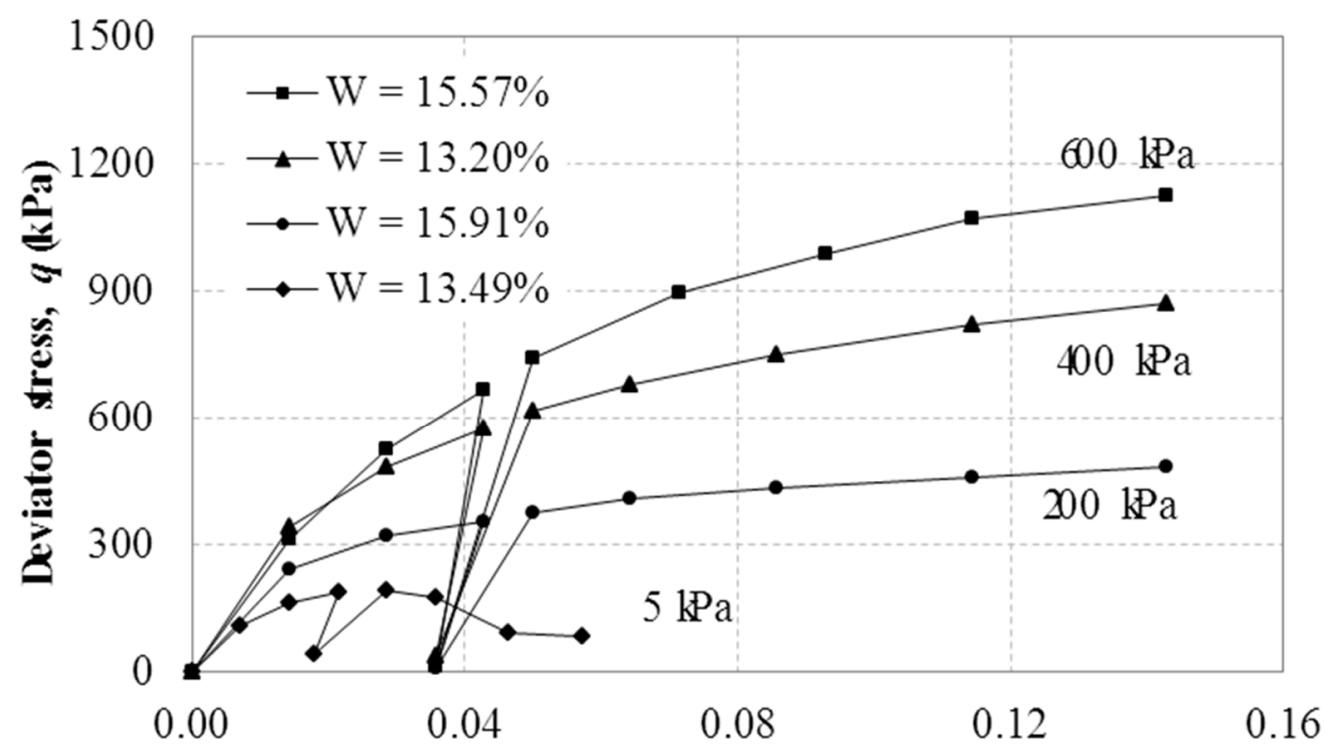

Axial strain, $\varepsilon$

(a)

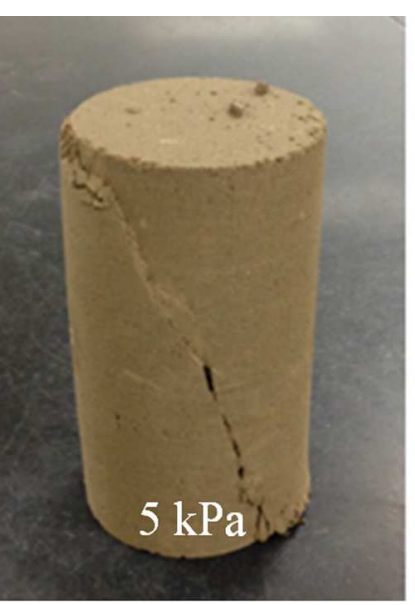

60

61 Fig. 6. (a) Stress strain curves under different confining stresses; (b) Specimens after tests.
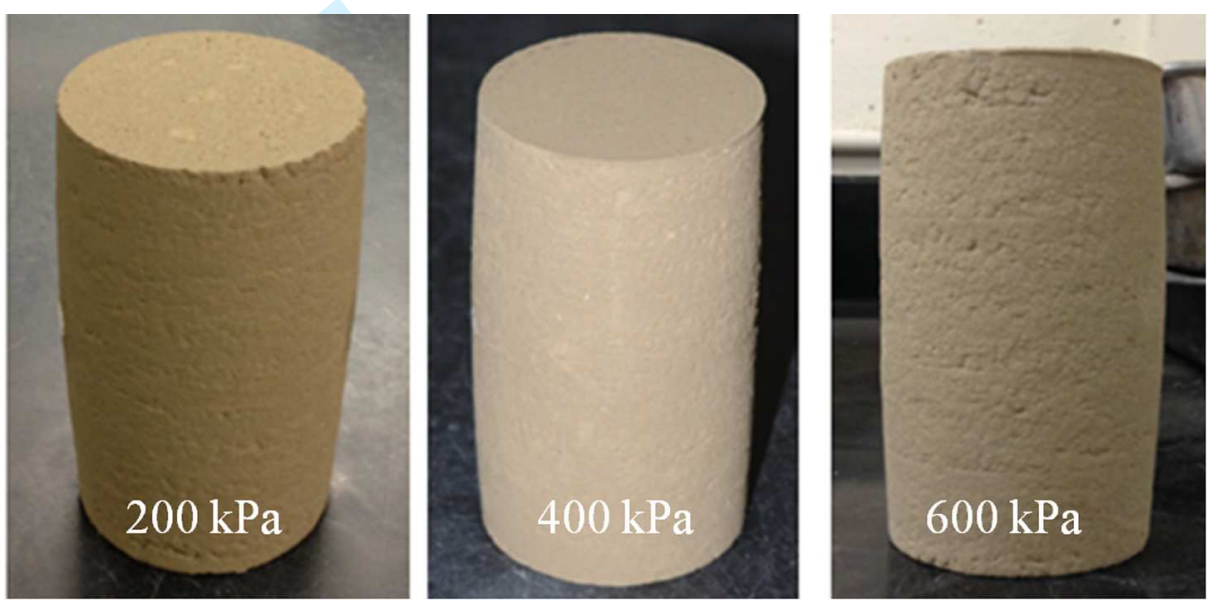

(b) 


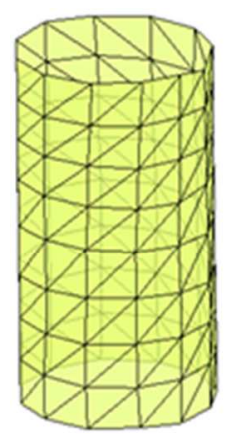

63

64

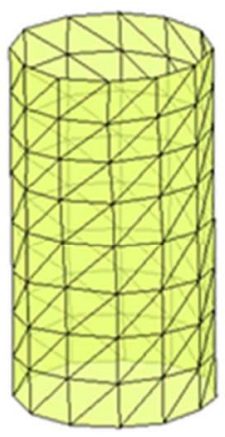

$0 \mathrm{~mm}$

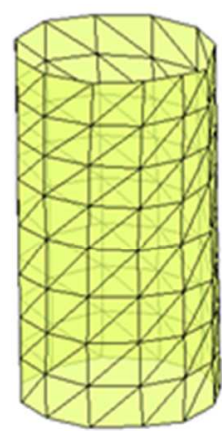

$1 \mathrm{~mm}$

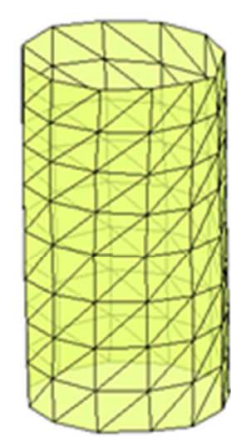

$3 \mathrm{~mm}$

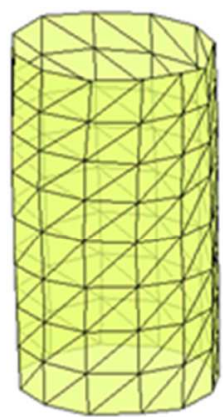

$6.5 \mathrm{~mm}$

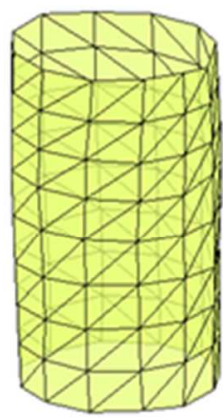

$8 \mathrm{~mm}$

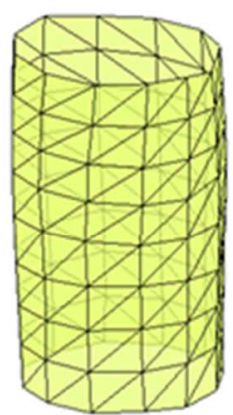

$10 \mathrm{~mm}$

(a)

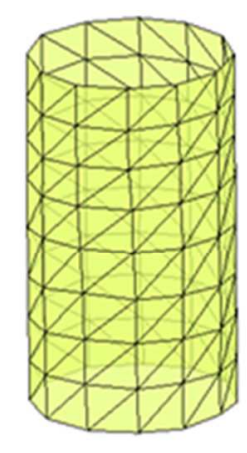

$2 \mathrm{~mm}$

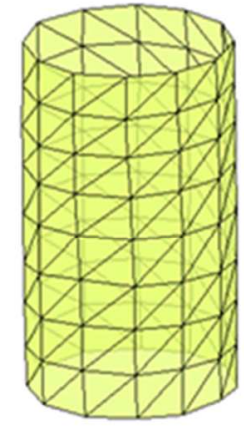

$6 \mathrm{~mm}$

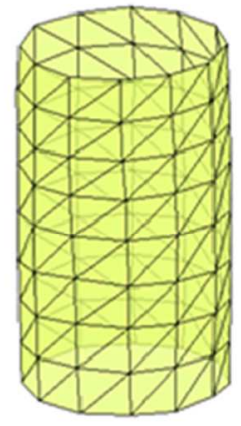

$12 \mathrm{~mm}$

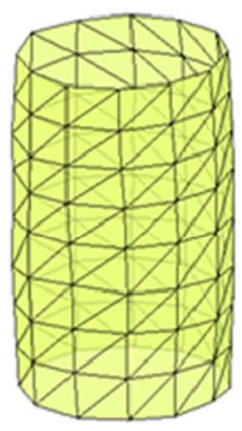

$16 \mathrm{~mm}$

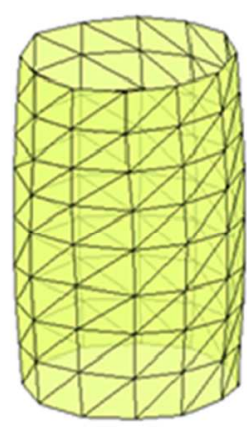

$20 \mathrm{~mm}$

66

(b)

Fig. 7. Soil deformations during deviatoric stage: (a) Specimen A (b) Specimen C.

68 


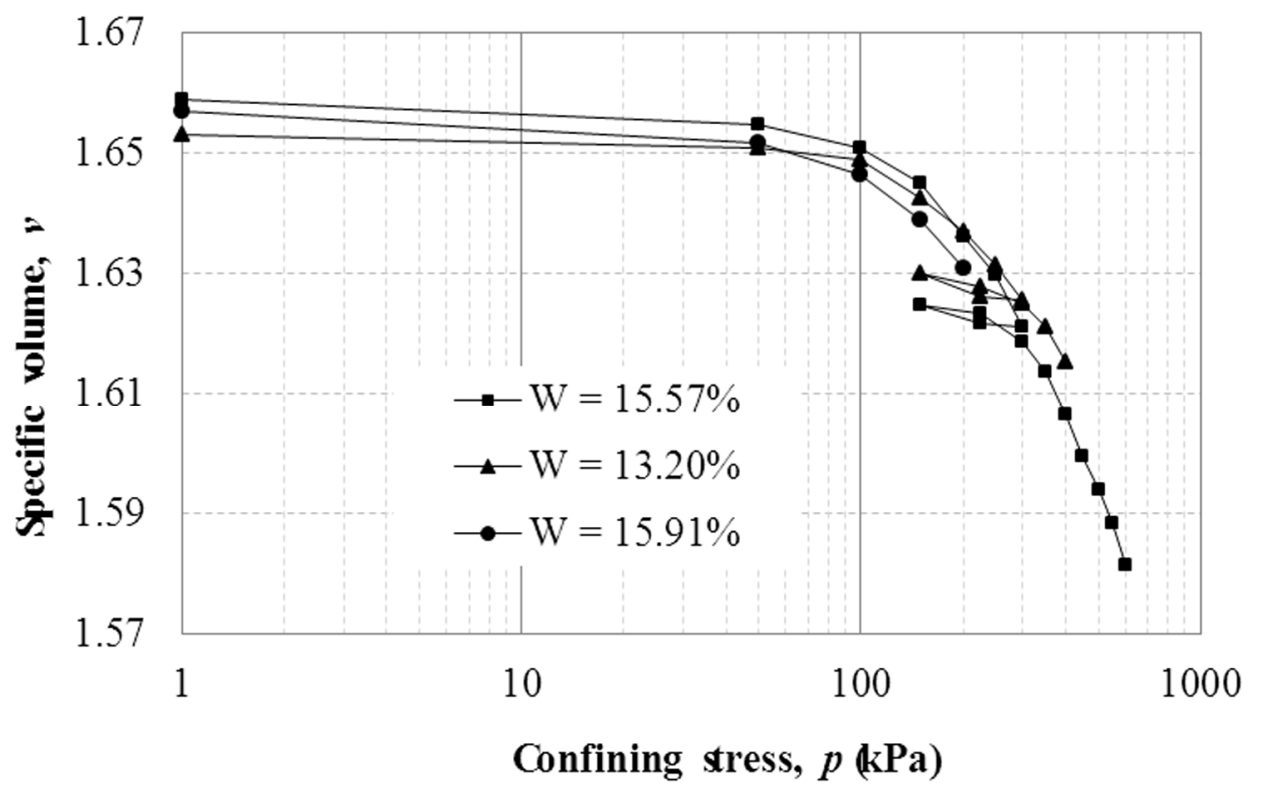

69

(a)

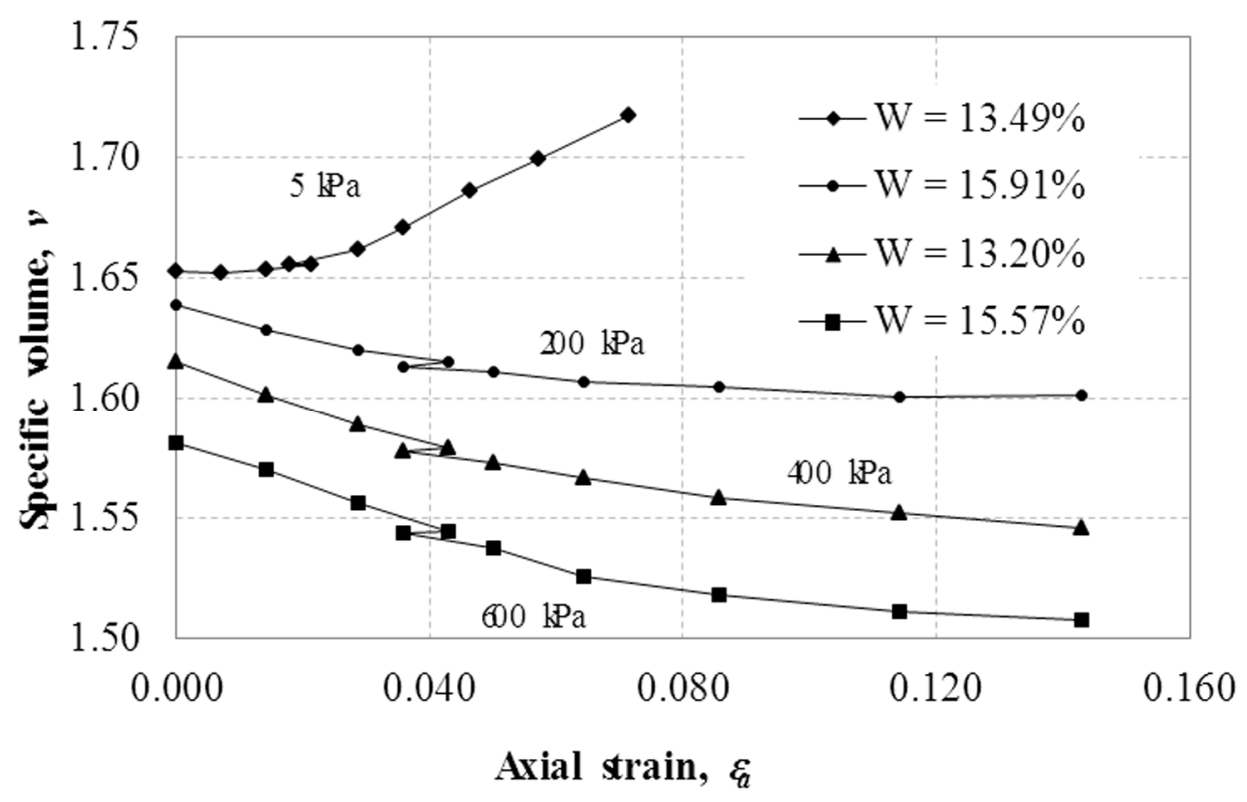

71

(b)

$73 \quad$ Fig. 8. (a) Soil volume variations during isotropic loading; (b) Soil volume variations during deviatoric loading under constant confining stresses. 


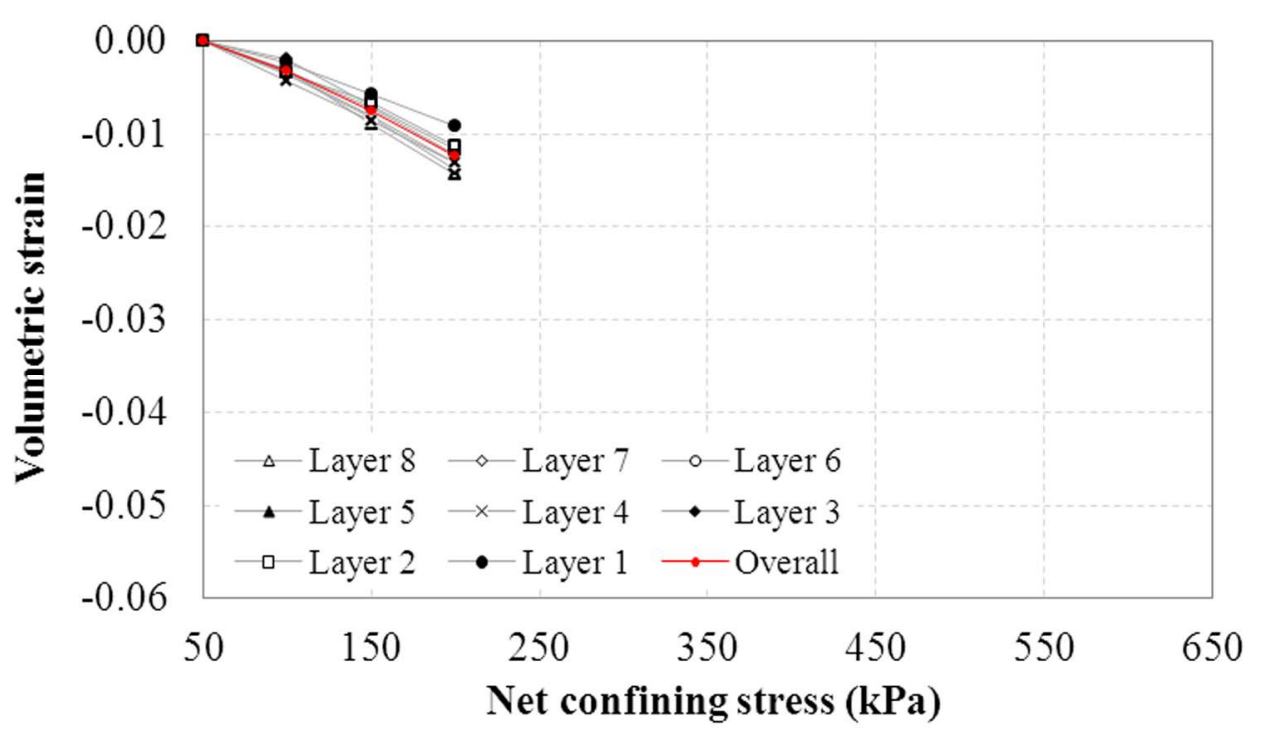

76

77

(a)

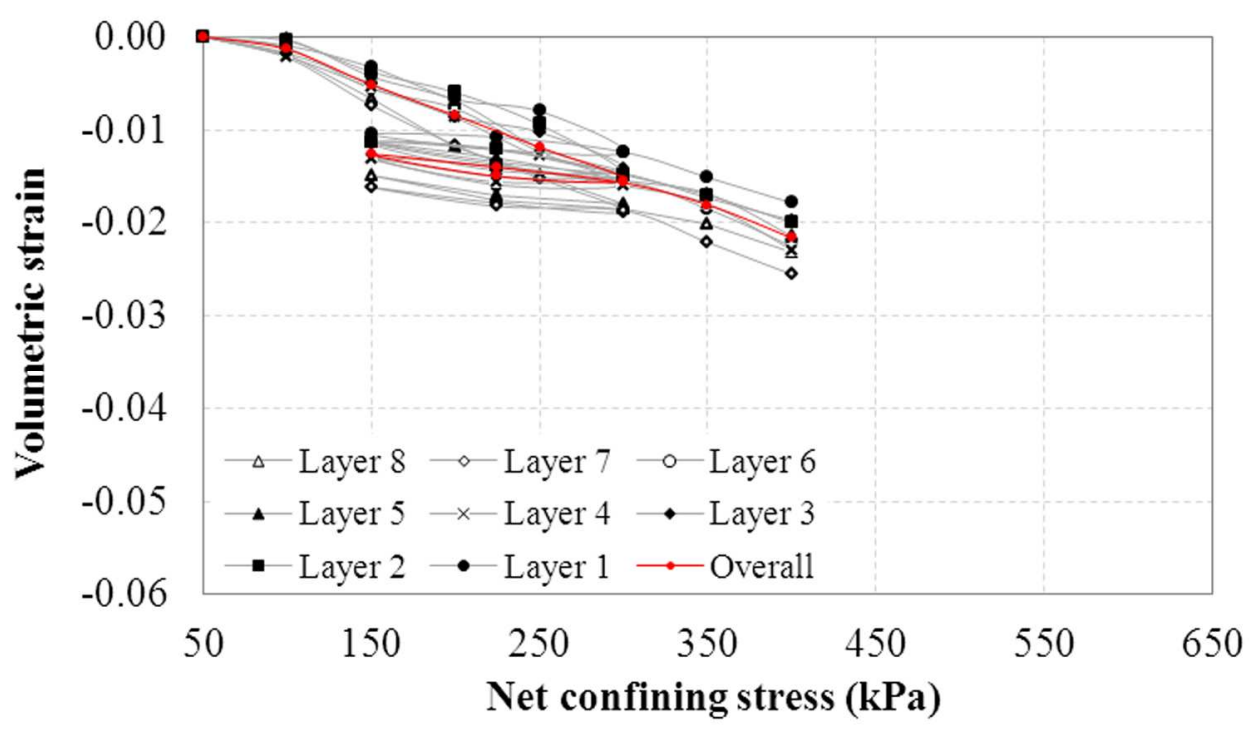

(b)

80

81 


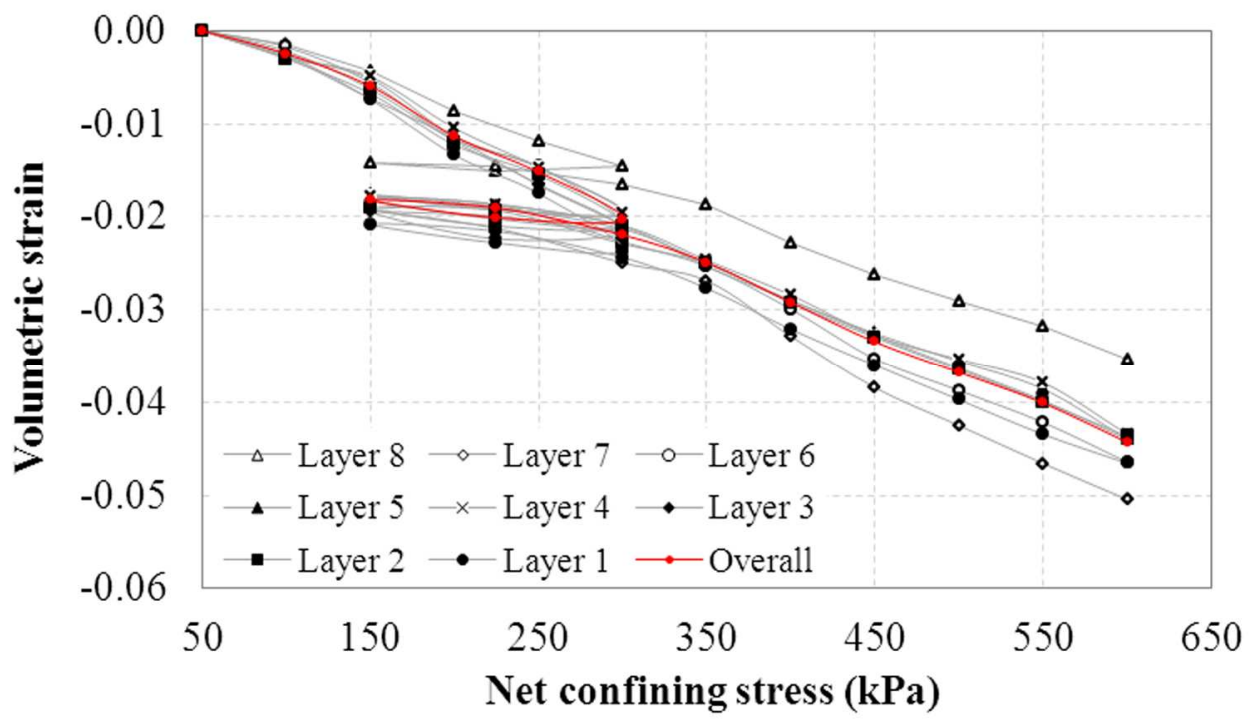

(c)

84 Fig. 9. Volumetric variations during isotropic loading: (a) Specimen B; (b) Specimen C; and (c) Specimen D. 


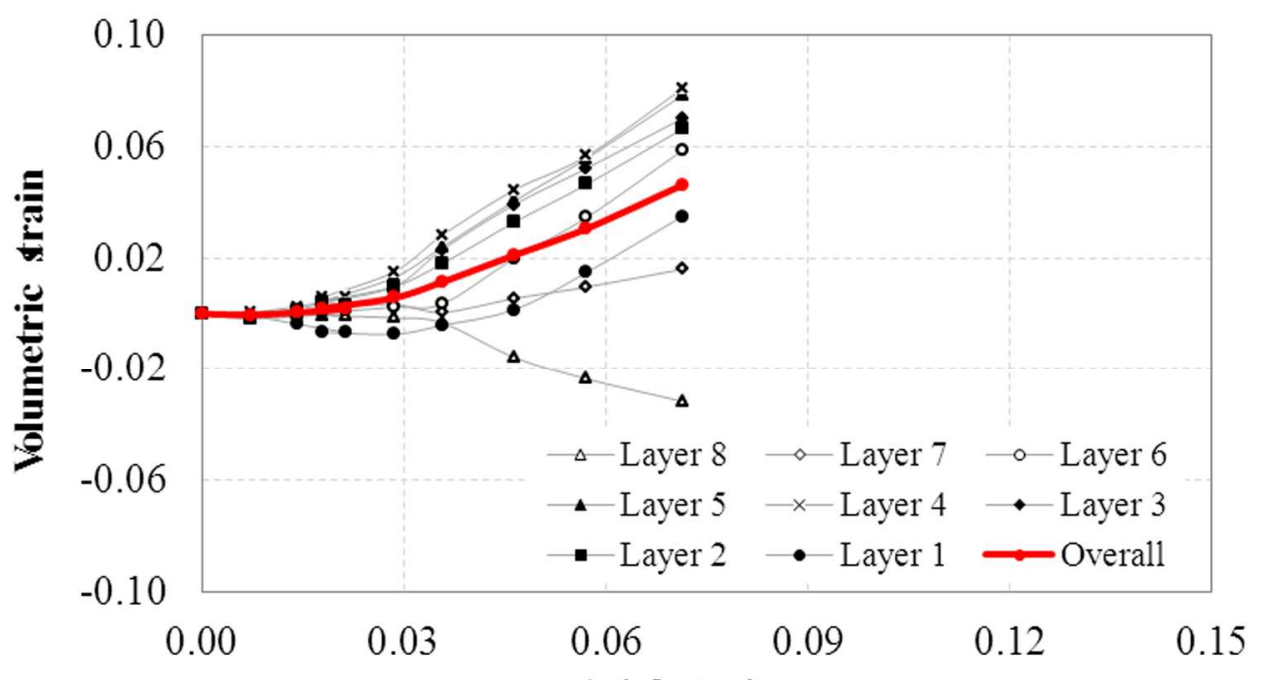

87 Axial strain

88

(a)

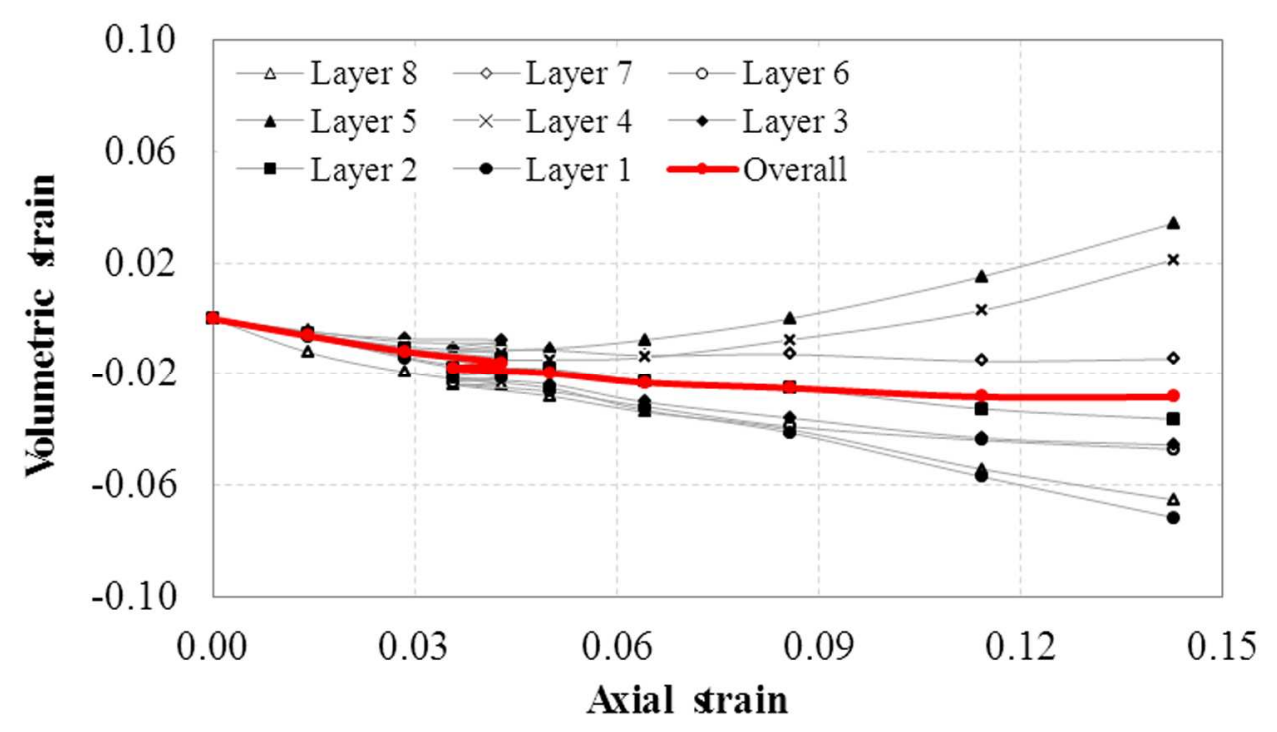

89

(b)

91

92 


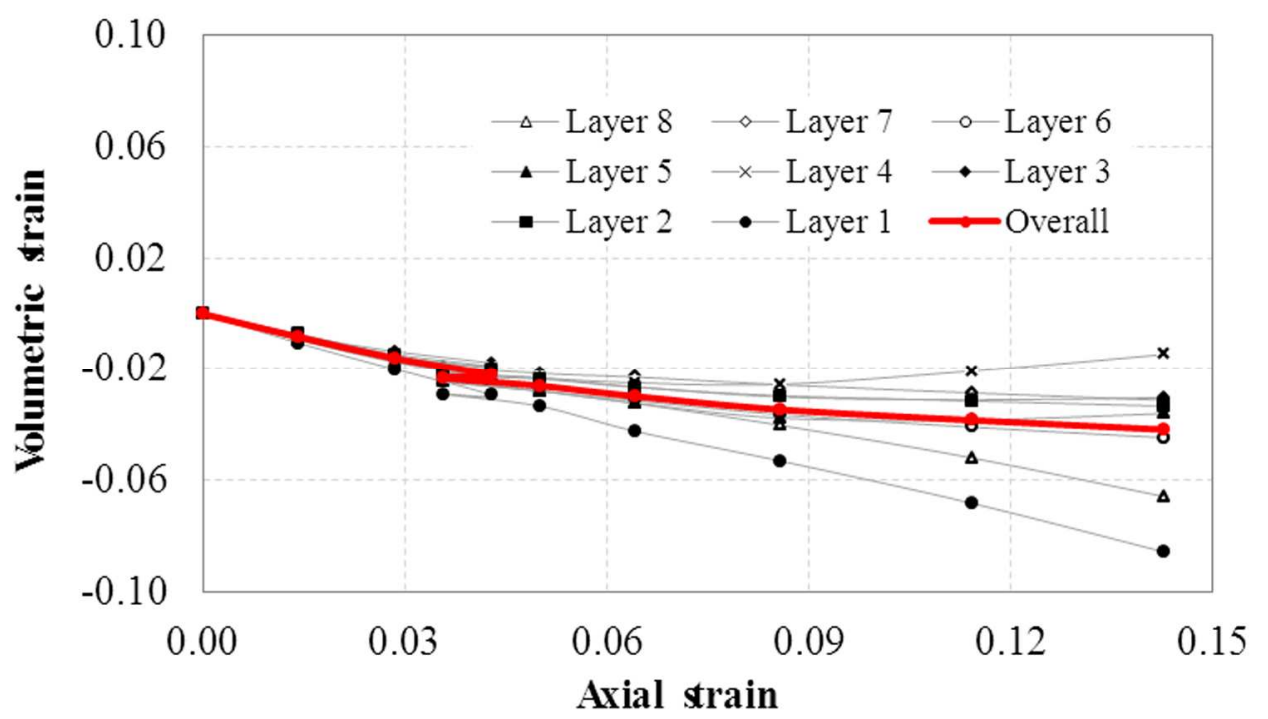

93

94

(c)

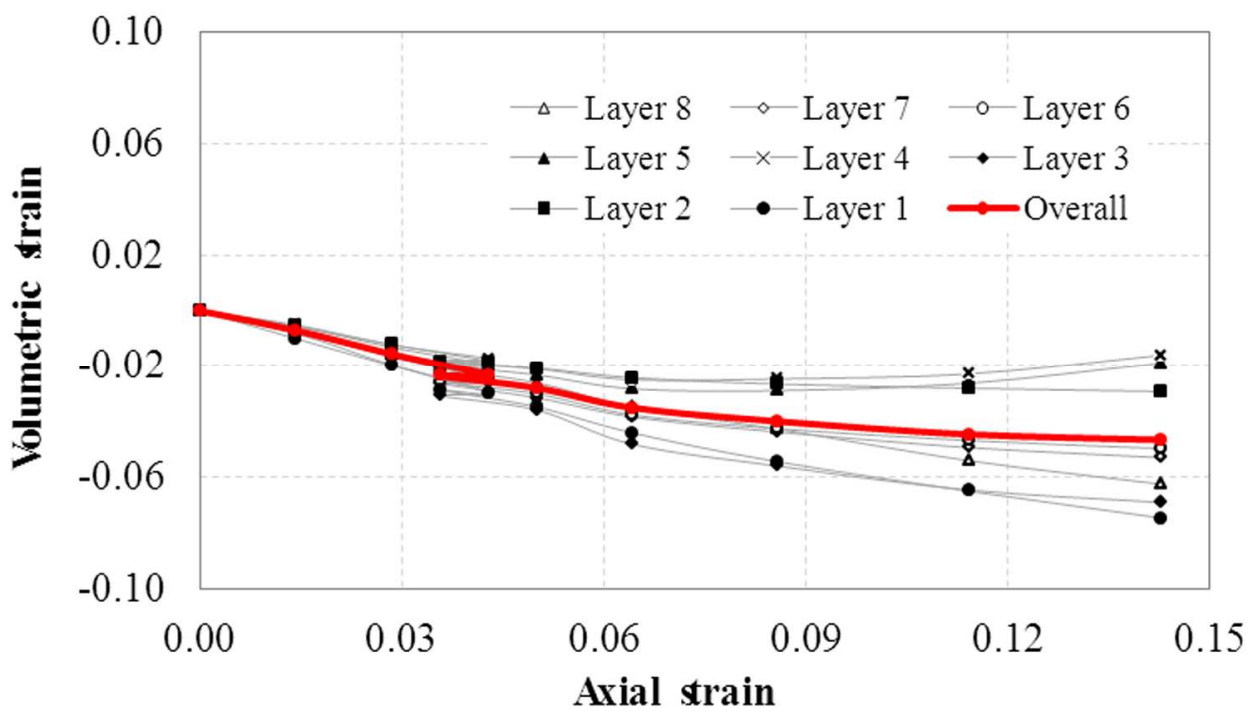

(d)

97 Fig. 10. Volumetric variations during deviatoric loading under different confining stresses:

(a) Specimen A; (b) Specimen B; (c) Specimen C; and (d) Specimen D.

99

100

101 

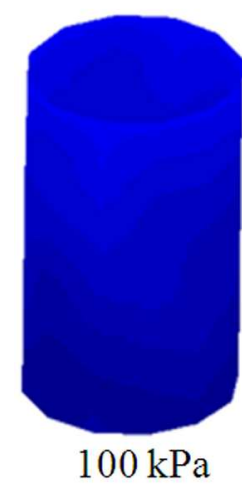

103

104

105

$100 \mathrm{kPa}$

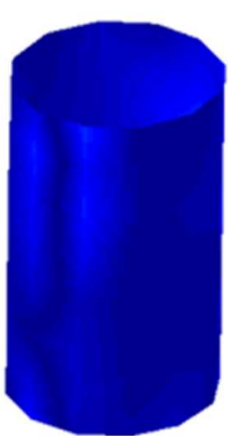

$100 \mathrm{kPa}$
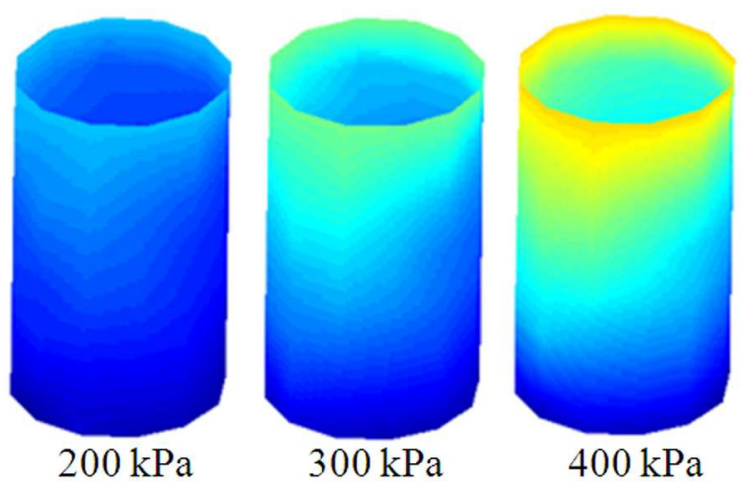

$400 \mathrm{kPa}$

(a)
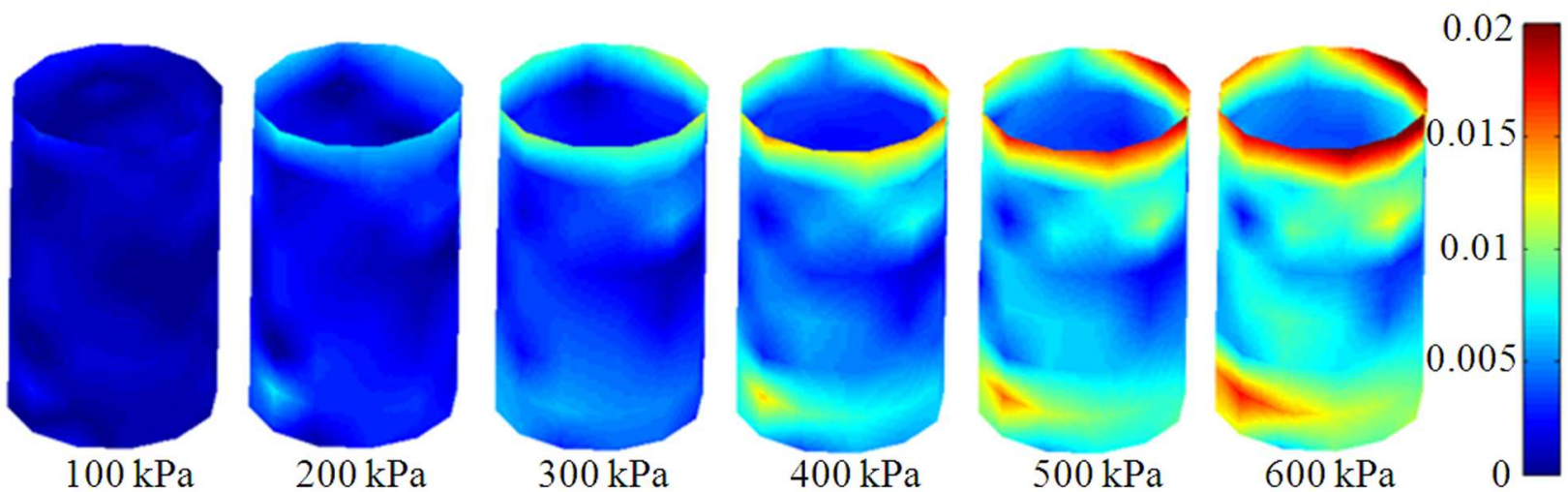

(b)

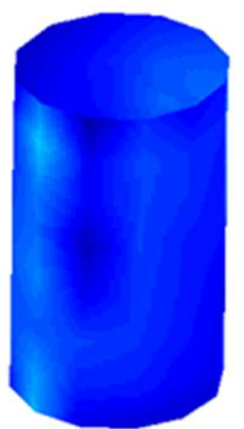

$200 \mathrm{kPa}$

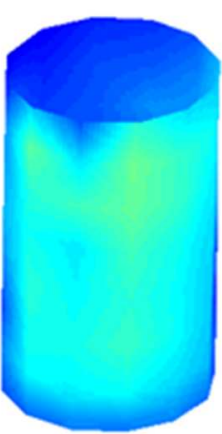

$300 \mathrm{kPa}$

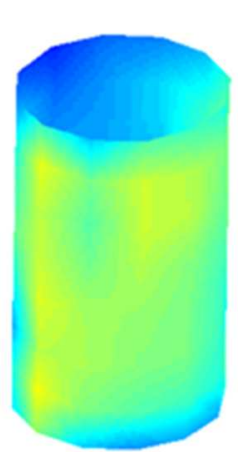

$400 \mathrm{kPa}$

(c)

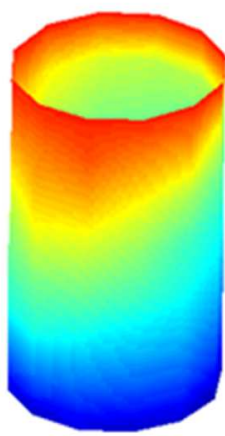

$500 \mathrm{kPa}$
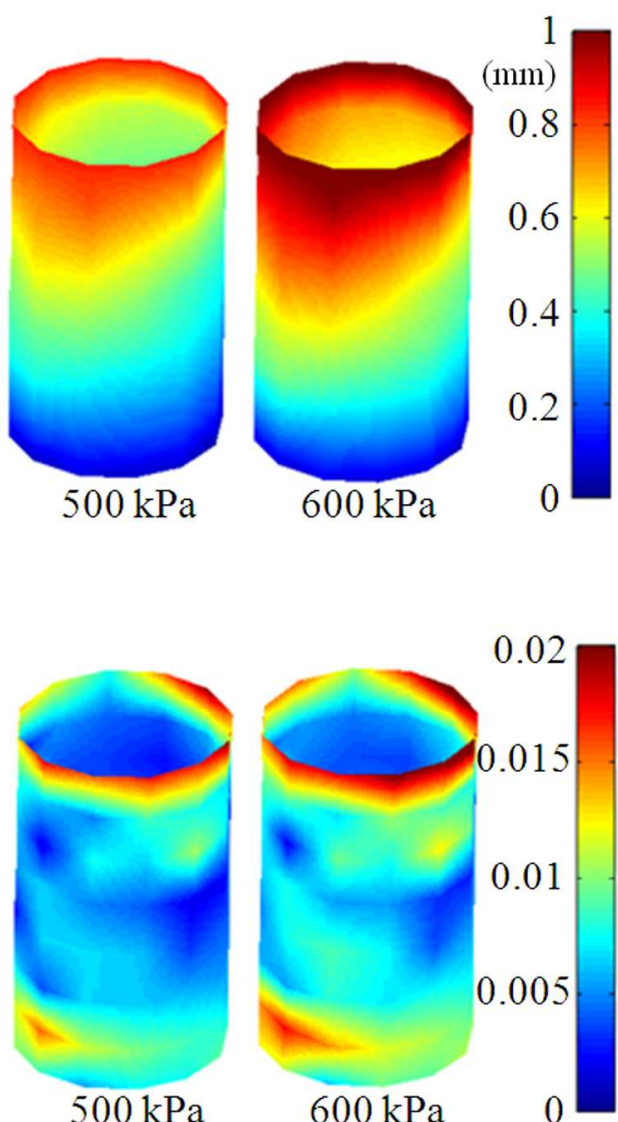

$600 \mathrm{kPa}$

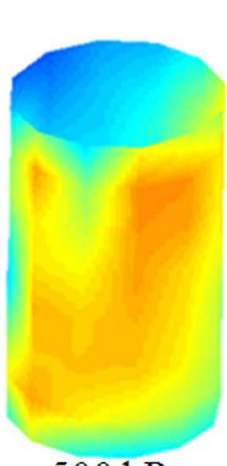

$500 \mathrm{kPa}$
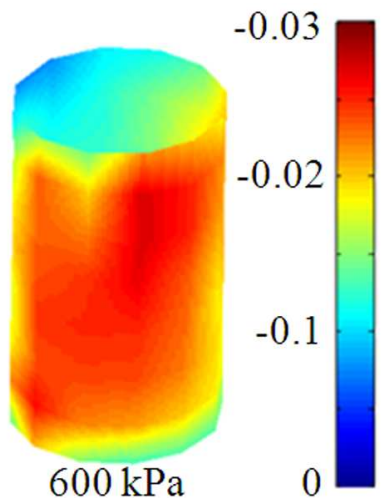

Fig. 11. Full-field deformation of specimen D during isotropic loading: (a) Axial displacement; (b) Axial strain; and (c) Radial strain. 


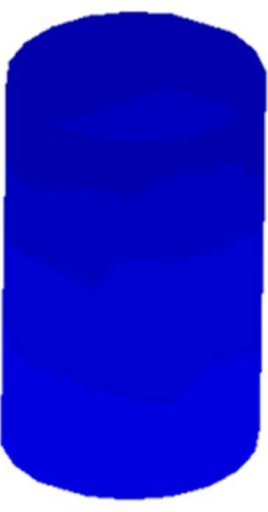

$1 \mathrm{~mm}$

113

114 115

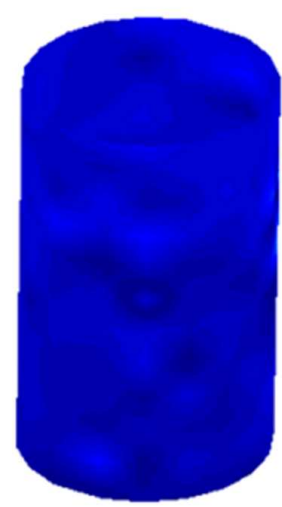

$1 \mathrm{~mm}$

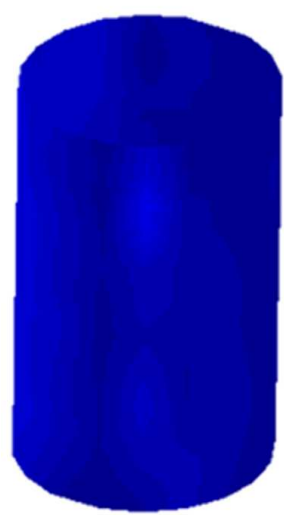

$1 \mathrm{~mm}$
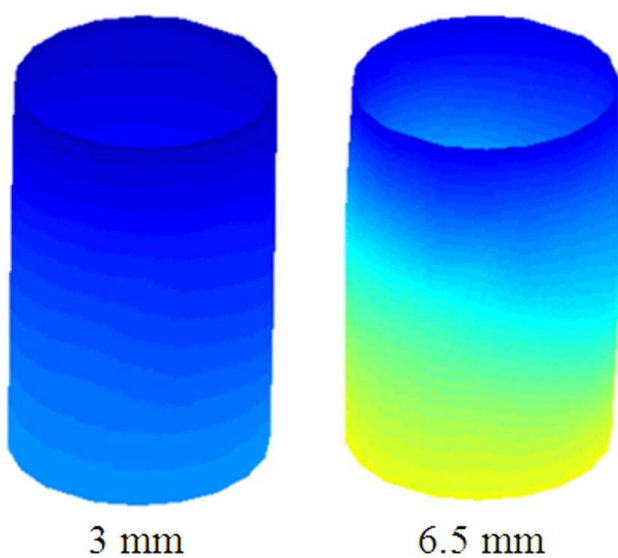

$6.5 \mathrm{~mm}$

(a)

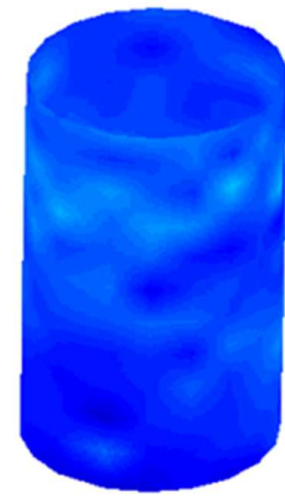

$3 \mathrm{~mm}$

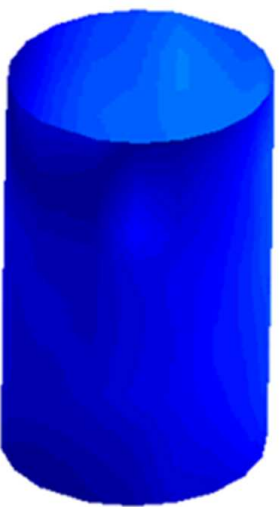

$3 \mathrm{~mm}$

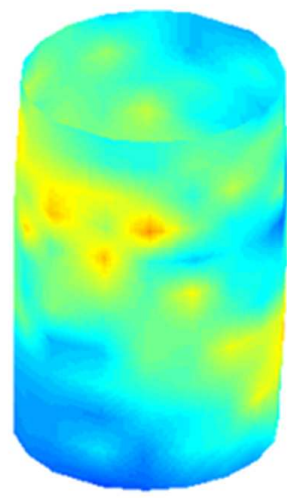

$6.5 \mathrm{~mm}$

(b)

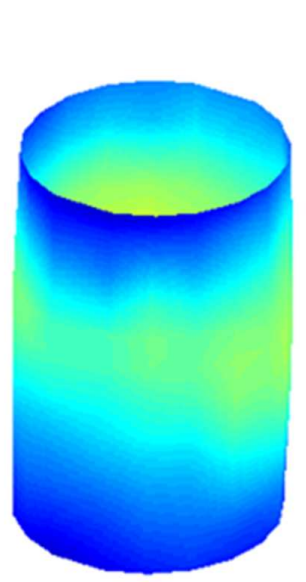

$6.5 \mathrm{~mm}$
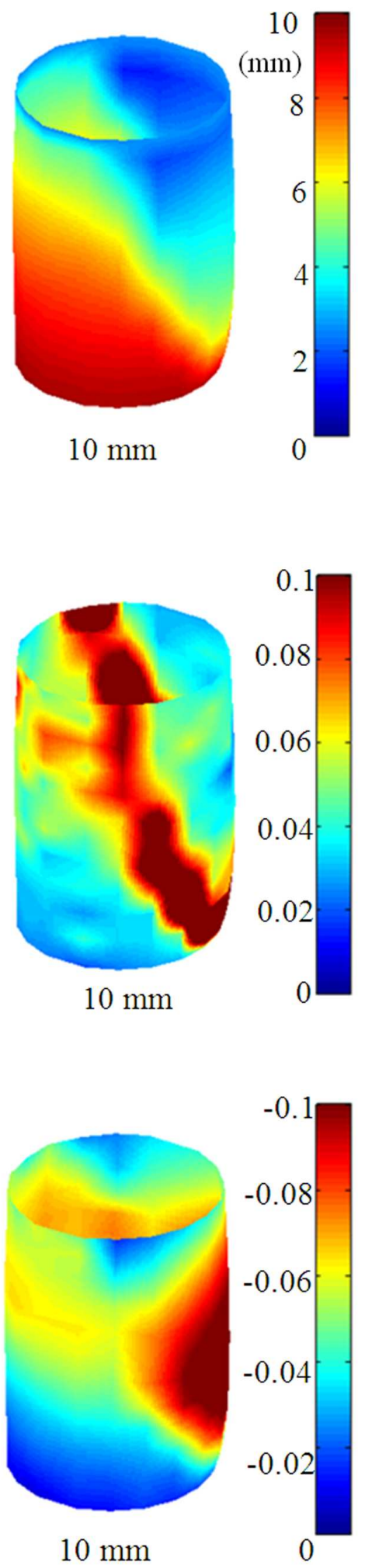

(c)

Fig. 12. Full-field deformation of specimen A during deviatoric loading under a confining stress of 5 kPa: (a) Axial displacement; (b) Axial strain; (c) Radial strain. 


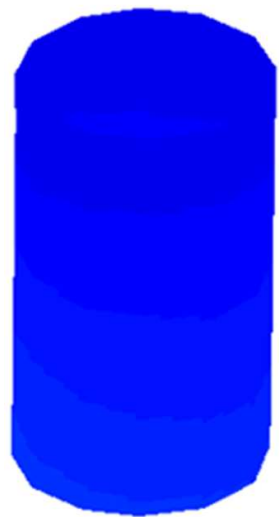

$2 \mathrm{~mm}$

121

122

123
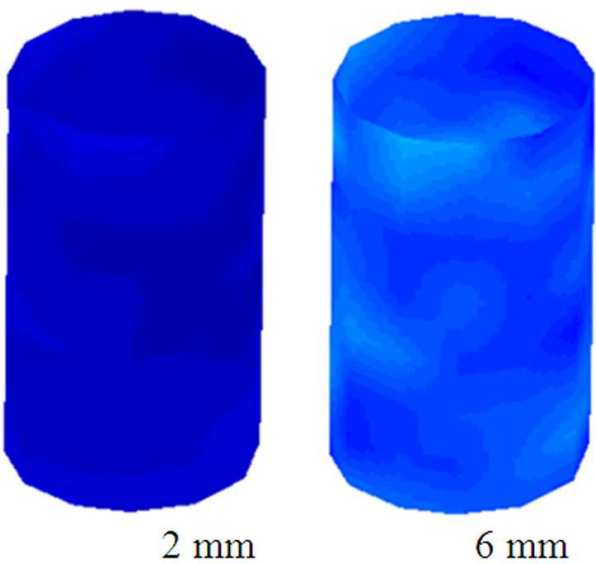

$6 \mathrm{~mm}$

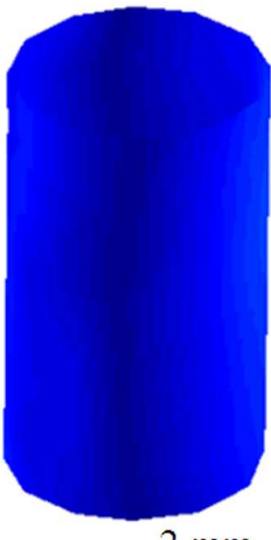

$2 \mathrm{~mm}$

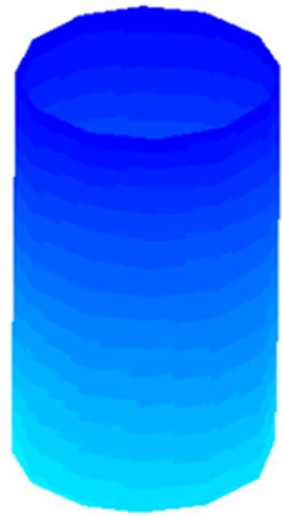

$6 \mathrm{~mm}$

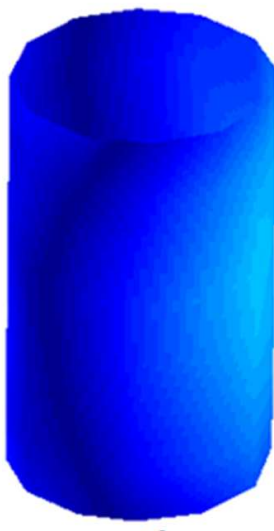

$6 \mathrm{~mm}$

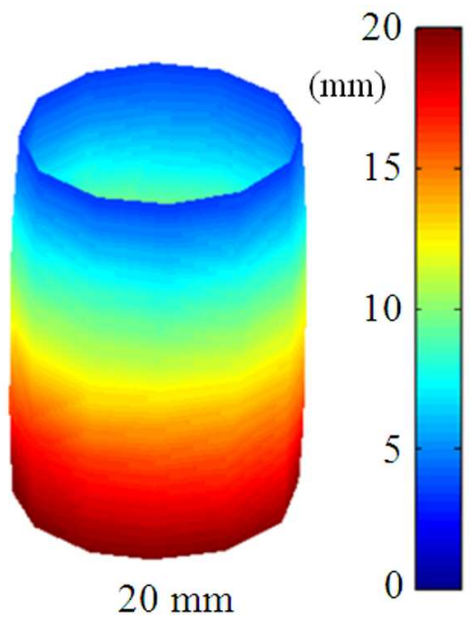

(a)

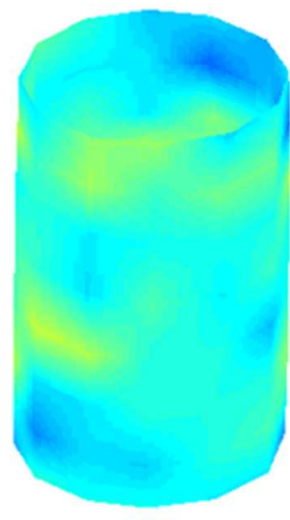

$12 \mathrm{~mm}$

(b)

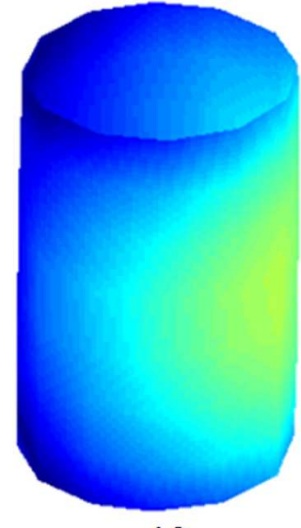

$12 \mathrm{~mm}$
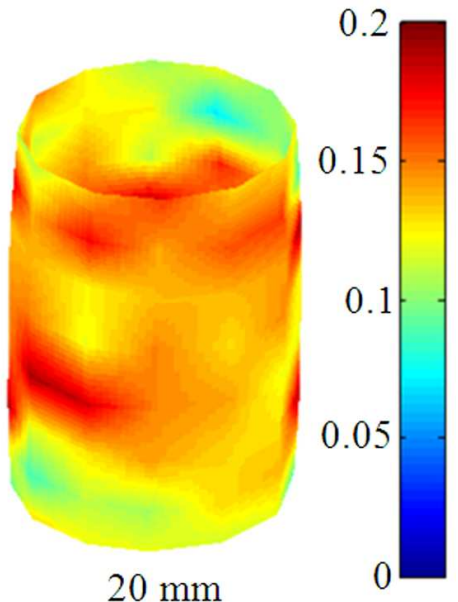

$20 \mathrm{~mm}$

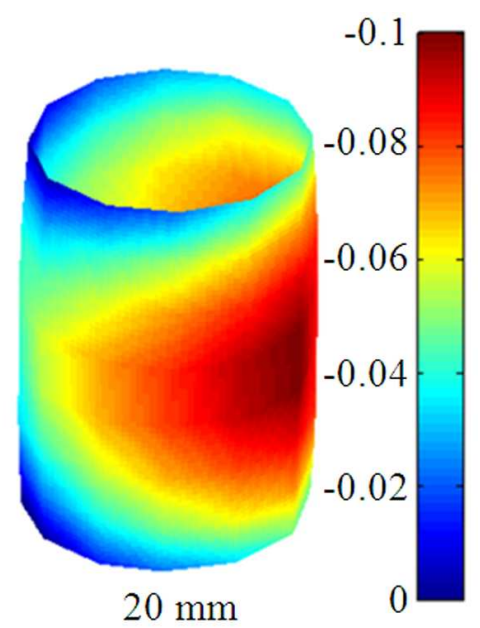

(c)

Fig. 13. Full-field deformation of specimen $\mathrm{C}$ during deviatoric loading under a confining stress of 400 kPa: (a) Axial displacement; (b) Axial strain; (c) Radial strain. 
Table 1 Camera calibration results.

\begin{tabular}{ccc}
\hline Parameter & Before Idealization & After Idealization \\
\hline$f(m m)$ & 53.3964 & 53.3964 \\
$M$ (pixel) & 4928 & 4928 \\
$N$ (pixel) & 3264 & 3264 \\
$F_{x}(\mathrm{~mm})$ & 23.9966 & 24.6565 \\
$F_{y}(\mathrm{~mm})$ & 15.8961 & 16.3292 \\
$P_{x}(\mathrm{~mm})$ & 12.0691 & 12.3283 \\
$P_{y}(\mathrm{~mm})$ & 8.0741 & 8.1646 \\
$K_{1}\left(10^{-5}\right)$ & 5.495 & 0 \\
$K_{2}\left(10^{-9}\right)$ & -4.673 & 0 \\
$P_{1}\left(10^{-6}\right)$ & -3.492 & 0 \\
$P_{2}\left(10^{-6}\right)$ & 1.501 & 0 \\
\hline
\end{tabular}


Table 2 Lease-square estimation results for point 93.

\begin{tabular}{|c|c|c|c|c|c|c|c|c|}
\hline Image ID & $d_{i}(\mathrm{~mm})$ & $\mathrm{X}(\mathrm{mm})$ & $\mathrm{Y}(\mathrm{mm})$ & $\mathrm{Z}(\mathrm{mm})$ & $d_{i}(\mathrm{~mm})$ & $\mathrm{X}(\mathrm{mm})$ & $\mathrm{Y}(\mathrm{mm})$ & $\mathrm{Z}(\mathrm{mm})$ \\
\hline 8 & 0.226 & \multirow{5}{*}{170.032} & \multirow{5}{*}{-79.605} & \multirow{5}{*}{4.338} & - & \multirow{5}{*}{170.012} & \multirow{5}{*}{-79.631} & \multirow{5}{*}{4.341} \\
\hline 9 & 0.031 & & & & 0.000 & & & \\
\hline 11 & 0.012 & & & & 0.024 & & & \\
\hline 12 & 0.013 & & & & 0.034 & & & \\
\hline 13 & 0.068 & & & & 0.034 & & & \\
\hline Average & 0.070 & & & & 0.023 & & & \\
\hline
\end{tabular}

5

6 
Table 3 Properties of the used soil.

\begin{tabular}{r|l}
\hline Properties & Value \\
\hline Maximum dry density & $1.836 \mathrm{~g} / \mathrm{cm}^{3}$ \\
Optimum moisture content & $15 \%$ \\
Specific gravity & 2.7 \\
Plastic limit & 18.2 \\
Liquid limit & 19.7 \\
Plastic index & 1.5 \\
\hline
\end{tabular}

8 
Table 4 Volumetric strains during deviatoric loading at different axial strain levels.

\begin{tabular}{|c|c|c|c|c|c|c|c|c|c|c|}
\hline \multirow{2}{*}{$\begin{array}{c}\text { Water } \\
\text { content }\end{array}$} & \multirow{2}{*}{$\begin{array}{c}\text { Confining } \\
\text { stress }\end{array}$} & \multicolumn{9}{|c|}{ Volumetric strain (\%) } \\
\cline { 3 - 12 } & & \multicolumn{3}{|c|}{$3.6 \%$ axial strain } & \multicolumn{2}{|c|}{$8.6 \%$ axial strain } & \multicolumn{3}{|c|}{$14.3 \%$ axial strain } \\
\cline { 3 - 12 } & Ave. & Std. & Max. & Ave. & Std. & Max. & Ave. & Std. & Max. \\
\hline $13.49 \%$ & $5 \mathrm{kPa}$ & 1.14 & 1.34 & 1.68 & - & - & - & - & - & - \\
\hline $15.91 \%$ & $200 \mathrm{kPa}$ & -1.81 & 0.52 & 0.74 & -2.51 & 1.64 & 2.52 & -2.83 & 3.87 & 6.25 \\
\hline $13.20 \%$ & $400 \mathrm{kPa}$ & -2.32 & 0.31 & 0.59 & -3.46 & 0.92 & 1.84 & -4.18 & 2.26 & 4.38 \\
\hline $15.57 \%$ & $600 \mathrm{kPa}$ & -2.36 & 0.49 & 0.71 & -3.99 & 1.21 & 1.6 & -4.66 & 2.26 & 3.06 \\
\hline
\end{tabular}

11 Ave.: represents the average volumetric strain.

12 Std.: represents the standard deviation of the volumetric strain.

13 Max.: represents the maximum difference between volumetric strain of each layer and the 14 corresponding overall volumetric strain. 
Table 5 Summarized axial and radial strains during isotropic loading.

\begin{tabular}{|c|c|c|c|c|c|c|c|c|c|}
\hline \multirow{3}{*}{$\begin{array}{c}\text { Water } \\
\text { content }\end{array}$} & \multicolumn{10}{|c|}{ Overall axial and radial Strain } \\
\cline { 2 - 11 } & \multicolumn{3}{|c|}{$200 \mathrm{kPa}$} & \multicolumn{3}{c|}{$400 \mathrm{kPa}$} & \multicolumn{3}{c|}{$600 \mathrm{kPa}$} \\
\cline { 2 - 11 } & $\varepsilon_{\mathrm{a}}$ & $\varepsilon_{\mathrm{r}}$ & $\varepsilon_{\mathrm{a}} / \varepsilon_{\mathrm{r}}$ & $\varepsilon_{\mathrm{a}}$ & $\varepsilon_{\mathrm{r}}$ & $\varepsilon_{\mathrm{a}} / \varepsilon_{\mathrm{r}}$ & $\varepsilon_{\mathrm{a}}$ & $\varepsilon_{\mathrm{r}}$ & $\varepsilon_{\mathrm{a}} / \varepsilon_{\mathrm{r}}$ \\
\hline $15.91 \%$ & 0.29 & 0.48 & 0.61 & - & - & - & - & - & - \\
\hline $13.20 \%$ & 0.22 & 0.32 & 0.69 & 0.51 & 0.83 & 0.61 & - & - & - \\
\hline $15.57 \%$ & 0.26 & 0.44 & 0.59 & 0.56 & 1.18 & 0.47 & 0.87 & 1.78 & 0.49 \\
\hline
\end{tabular}

